Document downloaded from:

http://hdl.handle.net/10251/74225

This paper must be cited as:

Herrera Gamboa, MP.; Medina Folgado, JR. (2015). Toe berm design for very shallow waters on steep sea bottoms. Coastal Engineering. 103:67-77.

doi:10.1016/j.coastaleng.2015.06.005.

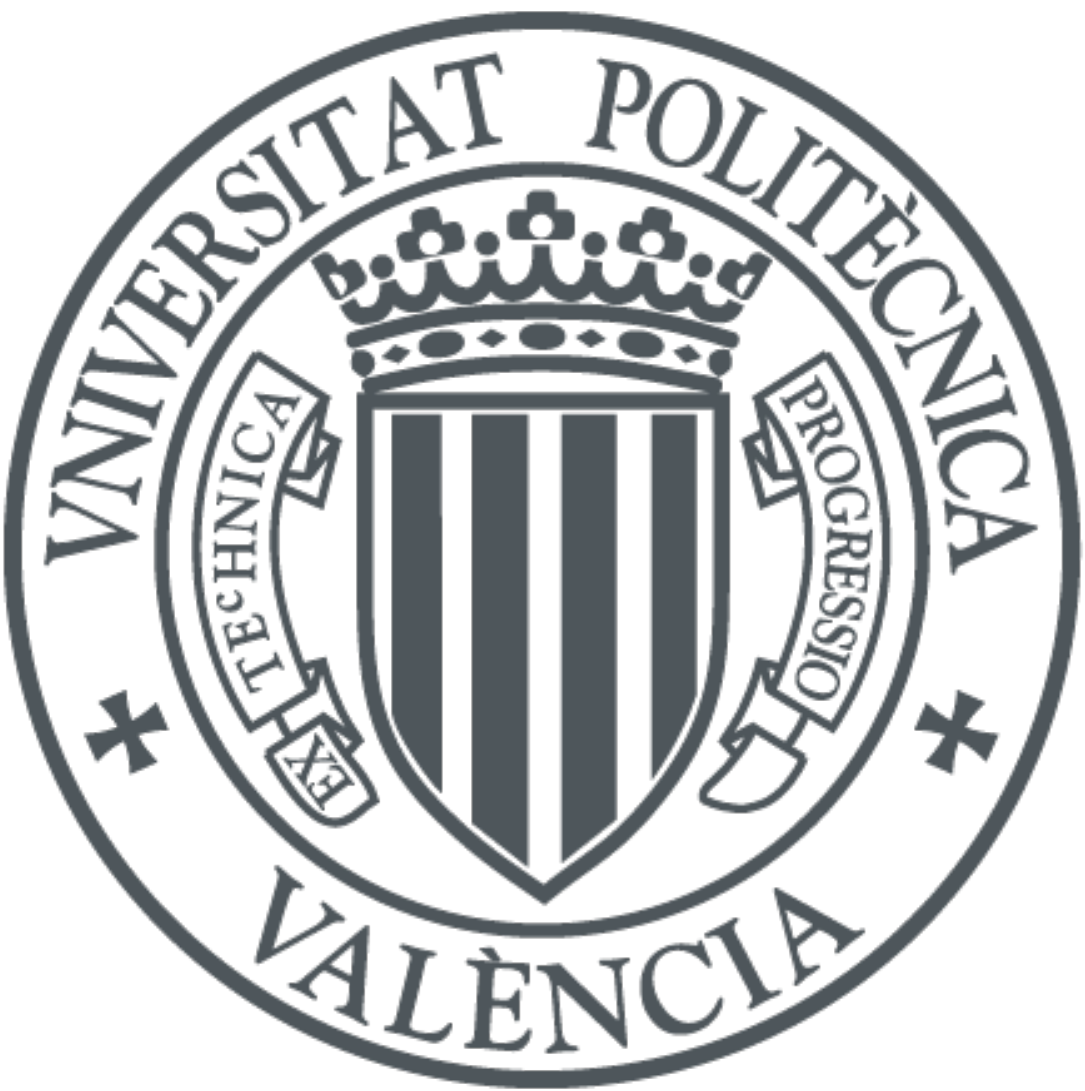

The final publication is available at

http://dx.doi.org/10.1016/j.coastaleng.2015.06.005

Copyright Elsevier

Additional Information 


\title{
Toe berm design for very shallow waters on steep sea bottoms
}

\author{
Maria P. Herrera ${ }^{a, *}$ and Josep R. Medina ${ }^{b}$ \\ ${ }^{a}$ Research Assistant, Dept. of Transportation, Universitat Politècnica de València, Camino de Vera s/n, 46022 \\ Valencia, Spain. E-mail: $\underline{\text { mahergam@upv.es }}$ ( ${ }^{*}$ corresponding author) \\ b Professor, Dept. of Transportation, Universitat Politècnica de València, Camino de Vera s/n, 46022 Valencia, Spain. \\ E-mail: jrmedina@upv.es
}

\section{ABSTRACT}

The toe berm is a relevant design element when rubble mound breakwaters are built on steep sea bottoms in breaking conditions. Different design formulas can be found in the literature to predict the damage caused to submerged toe berms placed on gentle bottom slopes. However, these formulas are not valid for very shallow waters in combination with steep sea bottoms where toe berms receive the full force of breaking waves. To guarantee breakwater stability in these conditions, new design formulas are needed for toe berms. To this end, physical model tests were carried out and data were analyzed to characterize rock toe berm stability in very shallow water and with a bottom slope $m=1 / 10$. Based on test results, a new formula was developed with three parameters to estimate the nominal diameter $\left(D_{n 50}\right)$ of the toe berm rocks: water depth at the toe $\left(h_{s}\right)$, deep water significant wave height $\left(H_{s 0}\right)$ and deep water wave length $\left(L_{o p}\right)$.

Keywords: Mound breakwater; Toe berm design; Shallow water; Steep sea bottom; Breaking conditions. 
Highlights:

a) In breaking conditions, toe berm stability is critically dependent on the bottom slope and water depth.

b) Existing formulas for toe berm design are mostly based on laboratory tests with submerged toe berms placed on gentle bottom slopes.

c) In shallow waters in combination with steep sea bottoms, wave attack may damage toe berms more than armor layers.

d) On rocky coastlines, mound breakwaters in very shallow water may require larger rocks for the toe berm than the armor.

\section{Introduction}

Rubble mound breakwaters are usually protected by a toe berm when concrete armor units are used for the armor layer. This toe berm is placed on the seafloor or a bed layer, providing support to the concrete armor units which are placed later on the structure slope (USACE, 2006). Fig.1 shows a typical cross section for a conventional mound breakwater with a toe berm placed on a steep seafloor, where $h_{s}$ is the sea bottom water depth at the toe, $h_{t}$ is the water depth above the toe berm, $B_{t}$ is the toe berm width and $t_{t}$ is the toe berm thickness. 


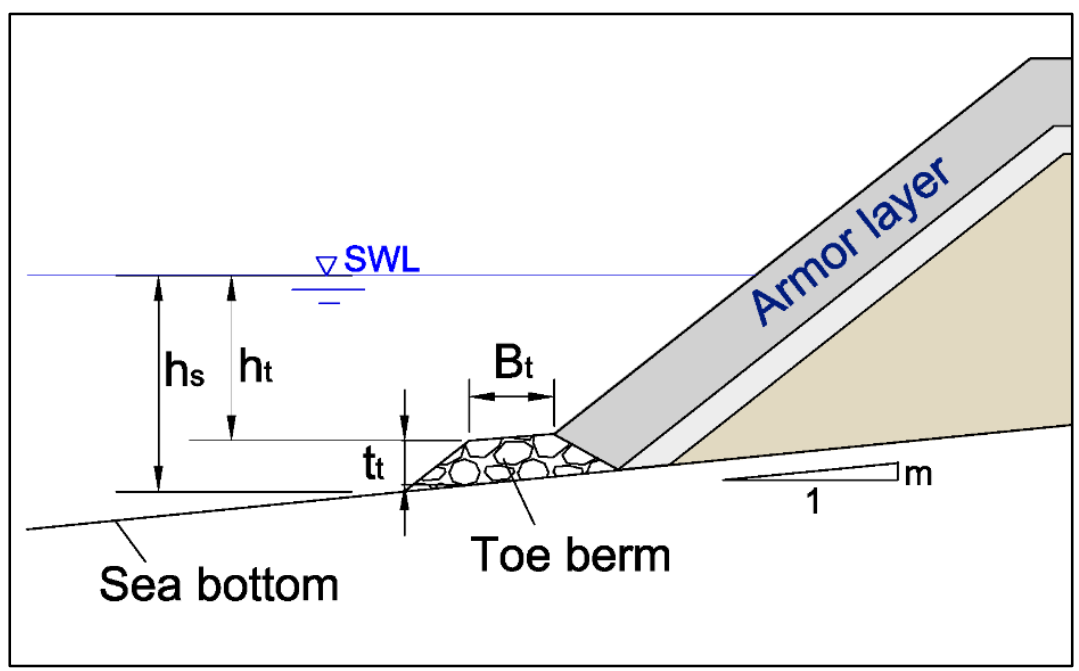

Fig. 1. Cross section of a conventional mound breakwater with a toe berm.

Many rubble mound breakwaters are constructed in breaking conditions and in shallow waters on steep sea bottoms. In these conditions, the highest waves start breaking on the sea bottom and impact the toe berm directly. This is particularly common for rocky sea bottoms with $m=1 / 10$ or higher slopes; in this case, the toe berm must be designed to guarantee armor stability. In very shallow waters combined with steep seafloors, the stone size required for the toe berm may significantly exceed the armor unit size.

Several empirical formulas have been developed to predict damage to rock toe berms in depth-limited conditions. Most were obtained from laboratory tests with gentle bottom slopes and are only valid for submerged toe berms $\left(h_{t}>>0\right)$; however, when constructed in very shallow waters on rocky coasts and steep seafloors, seawalls may require emerged toe berms $\left(h_{t}<0\right)$ built with large rocks.

This research focuses on the design of toe berms placed in very shallow waters $(-0.15<$ $\left.h_{s} / H_{s 0}<1.5\right)$ in combination with steep seafloors $(m=1 / 10)$ since these conditions have 
not yet received sufficient attention in the literature. New physical model tests were carried out in the wave flume at the Universitat Politècnica de València (Spain) and data were analyzed to determine the influence of shallow waters and steep seafloors on toe berm stability. In this paper, existing formulas to design toe berms are first compared. The experimental setup is then described, test results are analyzed and a new design formula with confidence intervals is provided. Finally, conclusions are drawn.

\section{Design formulas for toe berms}

In this section, the most relevant formulas to design quarrystone toe berms are examined. The stability number, $N_{s}=H_{s t} /\left(\Delta D_{n 50}\right)$, is used to characterize hydraulic stability, where $D_{n 50}$ is the nominal diameter of the rocks in the toe berm, $\Delta=$ $\left(\rho_{r}-\rho_{w}\right) / \rho_{w}$ is the relative submerged mass density, $\rho_{\mathrm{r}}$ is the mass density of the rocks, $\rho_{\mathrm{w}}$ is the mass density of the sea water, and $H_{s t}$ is the significant wave height at the toe of the structure.

Markle (1989) performed physical tests in breaking conditions with a bottom slope $m=$ 1/10. Regular waves were generated with increasing wave heights $\left(9.1<H_{m t}(\mathrm{~cm})<22.9\right)$ and wave periods $\left(1.32<T_{m}(\mathrm{~s})<2.82\right)$ for a given water depth at the toe $\left(h_{s}(\mathrm{~cm})=12.2\right.$, $15.2,18.3,21.3,24.4,27.4)$, where $H_{m t}$ is the average wave height at the toe of the structure and $T_{m}$ is the mean wave period. Four rock nominal diameters were used $\left(D_{n 50}(\mathrm{~cm})=2.58,2.95,3.30,4.06\right)$ for toe berms with $t_{t}=2 \cdot D_{n 50}$ and $B_{t}=3 \cdot D_{n 50}$. Eq. (1) is the lower bound formula obtained from Markle's data (see Muttray, 2013); the water 
depth ratio $\left(h_{t} / h_{s}\right)$ was identified as the determining parameter for toe berm stability.

Eq. (1) refers to moderate damage.

$N_{s}^{*}=\frac{H_{m t}}{\Delta D_{n 50}}=1.6+5.5 \cdot\left(\frac{h_{t}}{h_{s}}\right)^{3}$

where $N_{s}{ }^{*}=H_{m t} /\left(\Delta D_{n 50}\right)$ is the stability number for regular waves.

Gerding (1993) measured toe berm damage in physical tests using runs of 1,000 random waves and a bottom slope $m=1 / 20$. Tests were characterized by a constant wave steepness at the wave generating zone $\left(s_{g p}=2 \pi H_{s g} / g T_{p}^{2}=0.02\right.$ and 0.04$)$, an increasing significant wave height at the wave generator $\left(H_{s g}(\mathrm{~cm})=15,20,25\right)$ and a fixed water depth at the toe $\left(h_{s}(\mathrm{~cm})=30,40\right.$ and 50). Four stone sizes were tested $\left(D_{n 50}(\mathrm{~cm})=1.7,2.5,3.5\right.$ or 4.0$)$, varying the toe berm height $\left(t_{t}(\mathrm{~cm})=8,15\right.$ and 22$)$, and the toe berm width $\left(B_{t}(\mathrm{~cm})=12\right.$ and 20). Gerding (1993) also proposed using the damage number $N_{o d}$ to quantify the damage observed on the toe berm. $N_{o d}$ is defined as the number of displaced rocks in a strip as wide as $D_{n 50}$ of the toe berm. $N_{o d}$ is independent of the shape and volume of the toe berm; therefore, damage geometry may differ significantly from quantitative $N_{o d}$

$N_{o d}=\frac{N}{B / D_{n 50}}$

where $N$ is the number of displaced rocks and $B$ is the total width of the wave flume. After each test, the damage number $N_{\text {od }}$ was calculated and the model was rebuilt. The formula given by Gerding (1993) can be re-written to estimate toe berm damage as a function of the stability number. 


$$
N_{\text {od }}=\frac{1}{\left(0.24 \cdot\left(\frac{h_{t}}{D_{n 50}}\right)+1.6\right)^{1 / 0.15}} \cdot\left(N_{s}\right)^{1 / 0.15}
$$

Docters van Leeuwen (1996) conducted tests on a bottom slope $m=1 / 50$ to analyze the influence of the relative submerged mass density $\left(\Delta=\left(\rho_{r}-\rho_{w}\right) / \rho_{w}\right)$ on Gerding's formula, concluding that $\Delta$ was well reproduced since different stone mass densities gave similar results for $H_{s t} /\left(\Delta D_{n 50}\right)$ as a function of $h_{t} / D_{n 50}$.

Van der Meer (1998) re-analyzed the data given by Gerding (1993) for rock toe berms, using the water depth ratio $\left(h_{t} / h_{s}\right)$ as the explanatory variable; the new Van der Meer formula can be re-written as follows:

$$
N_{\text {od }}=\frac{1}{\left(6.2 \cdot\left(\frac{h_{t}}{h_{s}}\right)^{2.7}+2.0\right)^{1 / 0.15}} \cdot\left(N_{s}\right)^{1 / 0.15}
$$

CIRIA/ CUR/ CETMEF (2007) made reference to the formulas given by Gerding (1993) and Van der Meer (1998) to calculate the rock size for toe berms of rubble mound breakwaters. Gerding (1993) recommended using $N_{o d}=2.0$ for safe designs while Van der Meer (1998) recommended $N_{o d}=0.5$ for conservative designs. For a standard toe berm size of 3 to 5 rocks wide and a thickness of 2 to 3 rocks, CIRIA/ CUR/ CETMEF (2007) criteria indicated $N_{o d}=0.5$ for start of damage, $N_{o d}=2.0$ for moderate damage and $N_{o d}=4.0$ for failure.

Ebbens (2009) conducted physical tests to analyze the influence of three bottom slopes $(m=1 / 50,1 / 20$ and $1 / 10)$. Random waves were generated with seven water 
levels varying in the range of $7.3<h_{s}(\mathrm{~cm})<25.3$. The four lowest water levels $\left(h_{s}(\mathrm{~cm})=\right.$ 7.3, 9.3, 11.3 and 13.3) were tested with two values for wave steepness at the wave generating zone $\left(s_{g p}=2 \pi H_{s g} / g T_{p}^{2}=0.04\right.$ and 0.02$)$. Tests with the three highest water levels $\left(h_{s}(\mathrm{~cm})=15.3,20.3\right.$, or 25.3$)$ were only performed with $s_{g p}=2 \pi H_{s g} / g T_{p}^{2}=0.03$ for calibration. For each water level, wave runs were generated with four significant wave heights at the wave generator $\left(H_{s g}(\mathrm{~cm})=6,8,10\right.$ or 12$)$. Three rock sizes were tested $\left(D_{n 50}(\mathrm{~cm})=1.88,2.15\right.$ and 2.68) with toe berm thickness $t_{t}(\mathrm{~cm})=6$ and toe berm width $B_{t}(\mathrm{~cm})=10$ (above a $2 \mathrm{~cm}$-thick bed layer). Three rock porosities were used for each $D_{n 50}(n=0.36,0.33,0.32)$. For the bottom slope $m=1 / 10$, only $D_{n 50}(\mathrm{~cm})=2.15$ and 2.68 were tested. To characterize toe berm damage, the damage parameter given by Eq. (5) was used.

$N_{\%}=N \cdot \frac{D_{n 50}{ }^{3}}{(1-n) \cdot V_{\text {total }}}$

where $n$ is the void porosity and $V_{\text {total }}$ is the apparent volume of the toe berm.

A difference in damage was observed when varying the wave steepness from $s_{g p}=0.04$ to $s_{g p}=0.02$. Steeper waves $\left(s_{0 p}=0.04\right)$ led mainly to a downward movement of rocks, while longer waves $\left(s_{0 p}=0.02\right)$ pushed rocks in an upward direction. Thus, for tests with $s_{0 p}=0.04$, only downward rock movements were considered to characterize toe berm damage. For tests with $s_{0 p}=0.02$, the number of displaced rocks was counted considering the number of stones moving downwards (away from the toe berm) and upwards.

Using $N_{\%}$, Ebbens (2009) proposed the following design equation for toe berm stability: 
$N_{\%}=0.038 \cdot\left(\xi_{0 p} *\right)^{3 / 2} \cdot\left(N_{s}\right)^{3}$

where $\xi_{O p}{ }^{*}=\mathrm{m} /\left(H_{s t} / L_{O p}\right)^{1 / 2}$ is the surf similarity parameter in which $1 / m$ is the bottom slope, and $L_{O p}=g T_{p}^{2} / 2 \pi$ is the deep water wave length. Although higher toe berm damage was measured during the tests, Eq. (6) only provides reliable values if $N_{\%}<0.3$.

The toe berm was not rebuilt after each test but rather before each change in the water level. The cumulative toe berm damage did not always increase for a certain water depth, but it sometimes decreased when wave steepness increased $\left(s_{0 p}=0.04\right.$ after $\left.\mathrm{s}_{0 \mathrm{p}}=0.02\right)$.

Fig. 2 represents the experimental results given by Ebbens (2009) who recommended using $N_{\%}=5 \%\left(N_{o d} \approx 0.5\right)$ as a safe toe berm design level for swell waves and $N_{\%}=10 \%$ $\left(N_{o d} \approx 1.0\right)$ for wind waves. Fig. 2 also indicates the values of $N_{o d}$ and $N_{\%}$ obtained for toe berm sizes $\left(D_{n 50}(\mathrm{~cm})=1.88,2.15\right.$ and 2.68$)$, in which $\mathrm{N}_{\%}$ is approximately one order of magnitude lower than the damage number $N_{o d}$.

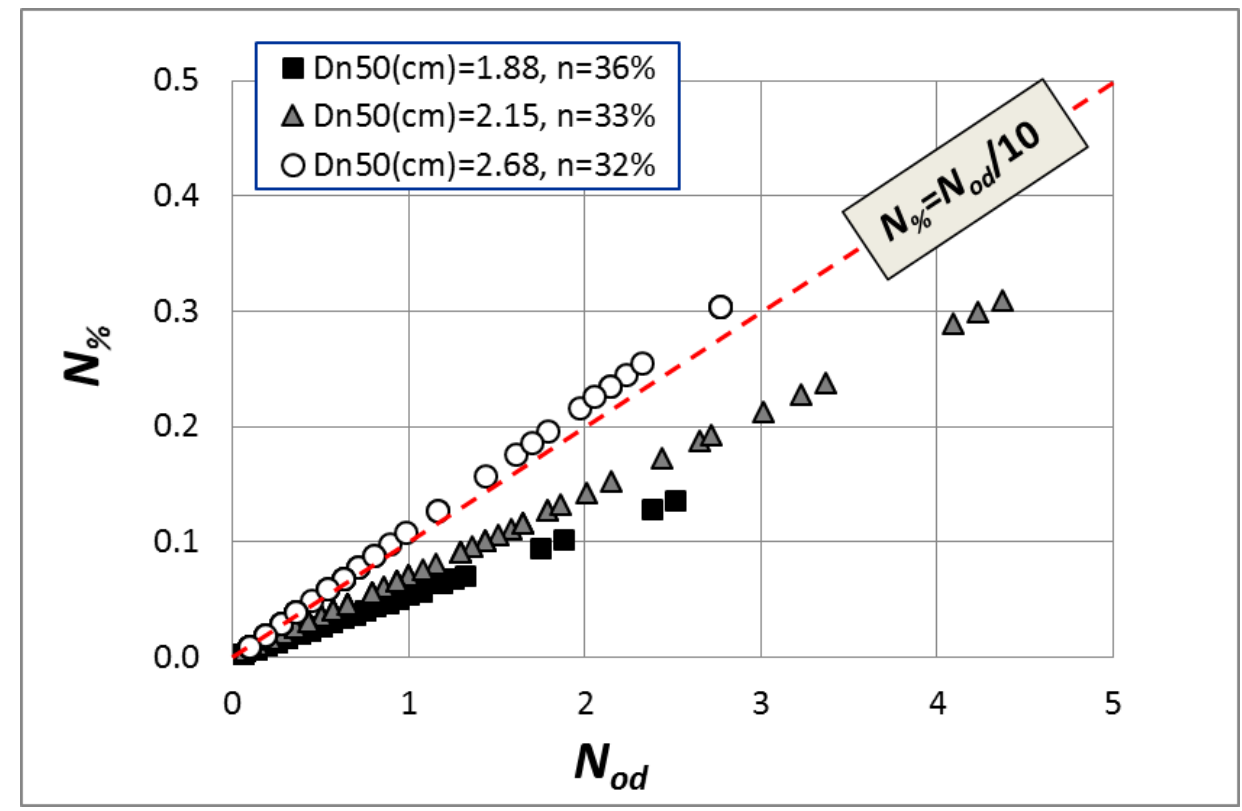


Fig. 2. Values of $N_{o d}$ corresponding to $N_{\%}$ measured by Ebbens (2009).

The experimental results obtained by Markle (1989), Gerding (1993) and Ebbens (2009) were re-analyzed by Muttray (2013), who proposed the following formula:

$N_{\text {od }}=\left(0.58-0.17 \cdot \frac{h_{t}}{H_{s t}}\right)^{3} \cdot\left(N_{s}\right)^{3}$

Van Gent and Van der Werf (2014) performed tests with runs of 1,000 random waves with $m=1 / 30$ bottom slope. Three water levels in front of the toe $\left(h_{s}(\mathrm{~cm})=20,30\right.$, and 40) were tested, mostly without severe wave breaking on the foreshore. Two wave steepness values at the wave generating zone were tested $\left(s_{g p}=2 \pi H_{s g} / g T_{p}^{2}=0.015\right.$ and 0.04 ) increasing the significant wave height until reaching a high damage level or $H_{s g}(\mathrm{~cm})=28$. Two stone sizes were used $\left(D_{n 50}(\mathrm{~cm})=1.46\right.$ and 2.33$)$ with a toe berm thickness $t_{t}=2 \cdot D_{n 50}$ and $4 \cdot D_{n 50}$, and a toe berm width $B_{t}=3 \cdot D_{n 50}$ and $9 \cdot D_{n 50}$. The model was rebuilt after each test series of four or seven wave runs of increasing $H_{s g}$. These authors proposed the following formula to estimate damage to the toe berm:

$N_{o d}=0.032 \cdot\left(\frac{t_{t}}{H_{s t}}\right) \cdot\left(\frac{B_{t}}{H_{s t}}\right)^{0.3} \cdot\left(\frac{\hat{u}_{\delta}}{\sqrt{g \cdot H_{s t}}}\right) \cdot\left(N_{s}\right)^{3}$

where $\hat{u}_{\delta}=\frac{\pi \cdot H_{s t}}{T_{m-1,0}} \frac{1}{\sinh \left(k h_{t}\right)}, k=\frac{2 \pi}{L_{m-1,0}}=\frac{2 \pi}{\frac{g}{2 \pi} \cdot T_{m-1,0}{ }^{2}}, T_{m-1,0}=\frac{m_{-1}}{m_{0}}$ and $m_{i}$ is the $i-$

th spectral moment, $m_{i}=\int_{0}^{\infty} S(f) \cdot f^{i} \cdot d f$, being $S(f)$ the wave spectra. 
Given a design wave storm $\left(H_{s t}, T_{m-1,0}\right)$, the larger the toe berm $\left(B_{t}\right.$ or $\left.t_{t}\right)$, the larger the $N_{o d}$

Eqs. (1) to (4) can be used to estimate the toe berm damage caused by a single wave storm, characterized by $H_{m t}$ or $H_{s t}$ measured at the toe of the structure. For Eqs. (6) and (7), the model was rebuilt after test series as defined by a given water. For Eq. (8), the model was rebuilt after test series as defined by a given wave steepness. Eqs. (6) to (8) also include the wave period $T_{p}$ or $T_{m-1,0}$ to characterize the design wave storm. Test characteristics are summarized in Table 1.

Table 1. Range of parameters ( $\mathrm{min}, \mathrm{max}$ ) used in the toe berm stability tests described in the literature and considered in this study.

\begin{tabular}{|c|c|c|c|c|c|c|}
\hline Parameter & Symbol & $\begin{array}{l}\text { Markle } \\
(1989)\end{array}$ & $\begin{array}{l}\text { Gerding } \\
(1993)\end{array}$ & $\begin{array}{l}\text { Ebbens } \\
(2009)\end{array}$ & $\begin{array}{l}\text { Van Gent } \\
\text { and Van der } \\
\text { Werf (2014) }\end{array}$ & This study \\
\hline Waves & - & Regular & Random & Random & Random & Random \\
\hline Bottom slope (-) & $m$ & $1 / 10$ & $1 / 20$ & $(1 / 50,1 / 10)$ & $1 / 30$ & $1 / 10$ \\
\hline Rock toe berm size $(\mathrm{cm})$ & $D_{n 50}$ & $(2.6,4.1)$ & $(1.7,4)$ & $(1.9,2.7)$ & $(1.5,2.3)$ & $(3.99,5.17)$ \\
\hline Water depth at toe $(\mathrm{cm})$ & $h_{s}$ & $(12.2,27.4)$ & $(30,50)$ & $(7.3,34.0)$ & $(20,40)$ & $(-2,20)$ \\
\hline $\begin{array}{l}\text { Relative water depth } \\
\text { at toe }(-)\end{array}$ & $h_{s} / D_{n 50}$ & $(3.0,10.6)$ & $(7.5,29.4)$ & $(2.7,18.0)$ & $(8.6,27.4)$ & $(-0.5,5.01)$ \\
\hline $\begin{array}{l}\text { Relative } \\
\text { significant wave } \\
\text { height at toe (-) }\end{array}$ & $H_{s t} / h_{s}$ & $(0.6,1.1)^{\mathrm{a}}$ & $(0.3,0.6)^{b}$ & $(0.2,1.4)$ & $(0.2,0.8)$ & $(-9.9,10.1)^{c}$ \\
\hline $\begin{array}{l}\text { Wave steepness at } \\
\text { toe }\left(s_{t p}=2 \pi H_{s t} / g T_{p}^{2}\right)(-)\end{array}$ & $s_{t p}$ & $(0.009,0.068)^{a}$ & $(0.01,0.04)^{b}$ & $(0.008,0.04)$ & $(0.012,0.042)$ & $(0.008,0.08)^{c}$ \\
\hline Relative toe width (-) & $B_{t} / D_{n 50}$ & 3 & $(3,12)$ & $(3.7,5.3)$ & 3 and 9 & 3 \\
\hline Relative toe thickness (-) & $t_{t} / D_{n 50}$ & 2 & $(2.3,8.8)$ & $(2.2,3.2)$ & 2 and 4 & 2 \\
\hline $\begin{array}{l}\text { Stability number at toe } \\
\left(N_{s}=H_{s t} t \Delta D_{n 50}\right) \quad \text { (note } \\
H_{s t}=H_{m 0} \text { at toe)(-) }\end{array}$ & $N_{s}$ & $(1.96,4.39)^{\mathrm{a}}$ & $(2.1,8.37)^{b}$ & $(1.07,4.16)$ & $(1.2,10.5)$ & $(0.81,3.36)^{c}$ \\
\hline
\end{tabular}




\begin{tabular}{|c|c|c|c|c|c|c|}
\hline Damage level (-) & $N_{o d}$ & moderate & $<9.2$ & $\leq 4.4$ & $<7.3$ & $<4.7$ \\
\hline Cumulative damage & - & no & no & yes & yes & yes \\
\hline $\begin{array}{l}\text { Number of waves per } \\
\text { run }\end{array}$ & $N$ & - & 1000 & 1000 & 1000 & 500 \\
\hline Number of test runs & $N_{t}$ & 1 & 1 & 4 & 4 to 7 & 35 to 40 \\
\hline
\end{tabular}

${ }^{\mathrm{a}}$ Refers to average wave height, $H_{m t}$, and wave period, $T_{m}$, at the toe of the structure.

${ }^{b}$ Refers to the average wave height of the one-third highest waves at the toe of the structure, $H_{s t}=H_{1 / 3}$.

c Refers to significant wave height measured at the wave generating zone, $H_{s g}=$ $\left(4 \cdot m_{0}\right)^{1 / 2}$.

Fig. 3 shows an example of a typical case $\left(B_{t}=3 \cdot D_{n 50}\right.$ and $\left.t_{t}=2 \cdot D_{n 50}\right)$ of toe berm damage estimated by Eqs. (3) to (8) as a function of $N_{s}$. The wave steepness at the toe is fixed at $s_{t p}=2 \pi H_{s t} / g T_{p}^{2}=0.02$, the water depth ratio is $h_{t} / h_{s}=0.78$, and the relative water depth at the toe is $h_{s} / D_{n 50}=9.4$. The damage parameter obtained from Eq. (6) was considered $N_{\%}=N_{o d} / 10$ (see Fig. 2). 


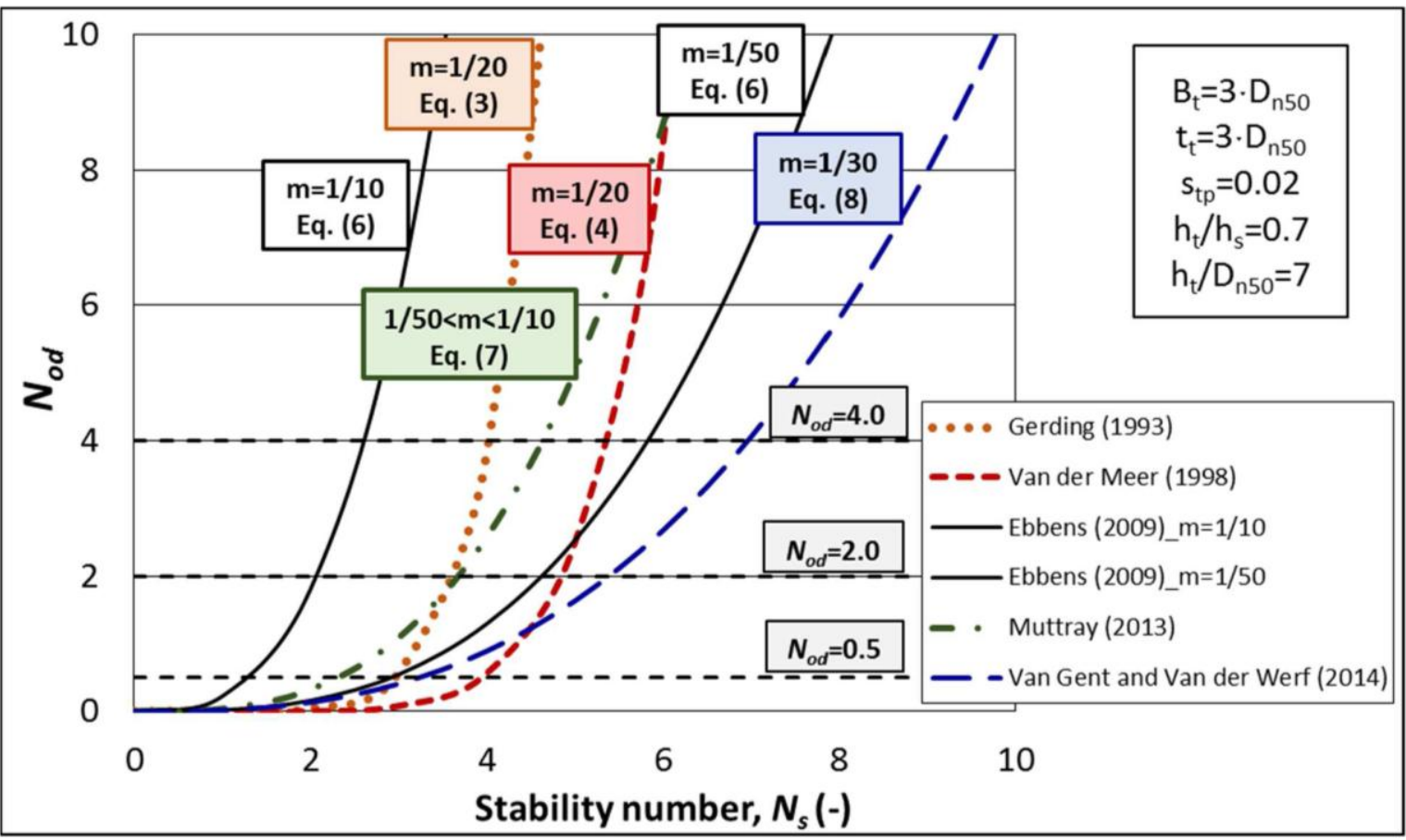

Fig. 3. Example of toe berm damage estimated by different formulas.

Fig. 3 illustrates the relevant dispersion of toe berm damage estimations calculated using Eqs. (3), (4) and (6) to (8).

The available literature for submerged toe structures in depth-limited conditions and gentle seafloors suggests that the primary parameters for toe stability are the relative water depth at the toe and the wave height, while other parameters such as berm width/berm height appear to be less relevant (see e.g. Van Gent and Van der Werf, 2014). However, for emergent toe structures and steeper seafloors no information is available. Only Ebbens (2009) performed physical tests with random waves and a steep bottom $(m=1 / 10)$. Nevertheless, the effect of water depth on toe berm stability was not considered nor was the stability of emerged toe berms. 
In this paper, the influence of the water depth in submerged $\left(h_{t}>0\right)$ and emerged $\left(h_{t}<0\right)$ toe berms is investigated, considering the cumulative toe berm damage corresponding to a variety of wave storm conditions with the same still water level (SWL).

\section{Methodology}

2D physical model tests were conducted in the wind and wave test facility $(30 \times 1.2$ $\mathrm{x} 1.2 \mathrm{~m}$ ) of the Laboratory of Ports and Coasts at the Universitat Politècnica de València (LPC-UPV) with a steep sea bottom $(m=1 / 10)$. Fig. 4 shows a longitudinal cross section of the LPC-UPV wave flume while Fig. 5 shows the cross section of the model tested.

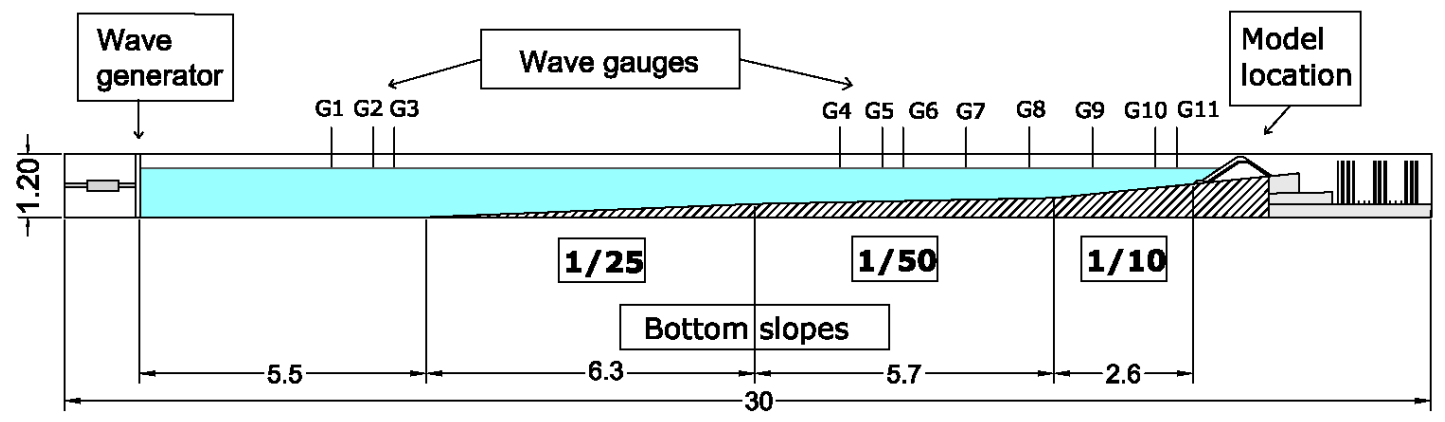

Fig. 4. Longitudinal cross section of the LPC-UPV wave flume (dimensions in meters).

The model depicted in Fig. 5 is a conventional $\tan \alpha=H / V=1.5$ non-overtopping mound breakwater, protected with a conventional double-layer randomly-placed cube armor with nominal diameter $D_{n}(\mathrm{~cm})=3.97$ and $W(\mathrm{~g})=141.5$. The mean value of the measured packing density of the tested armor layer was $\phi=1.16$, very close to the recommended value $\phi=1.17$ given by CIRIA/ CUR/ CETMEF (2007). Rocks with $D_{n 50}(\mathrm{~cm})=3.99$ and 5.17 and mass density $\rho_{r}\left(\mathrm{~g} / \mathrm{cm}^{3}\right)=2.70$ were used for the toe 
berms. Toe berm thickness and width were fixed at $t_{t}=2 \cdot D_{n 50}$ and $B_{t}=3 \cdot D_{n 50}$, similar to those tested by Markle (1989), Gerding (1993), Ebbens (2009) and Van Gent and Van der Werf (2014).

The double-layer randomly-placed cube armor was built on a filter layer with $D_{n 50}(\mathrm{~cm})$ $=1.78$ and $D_{n 85} / D_{n 15}=1.35$. The characteristics of the core material were $D_{n 50}(\mathrm{~cm})=$ 0.68 and $D_{n 85} / D_{n 15}=1.64$.

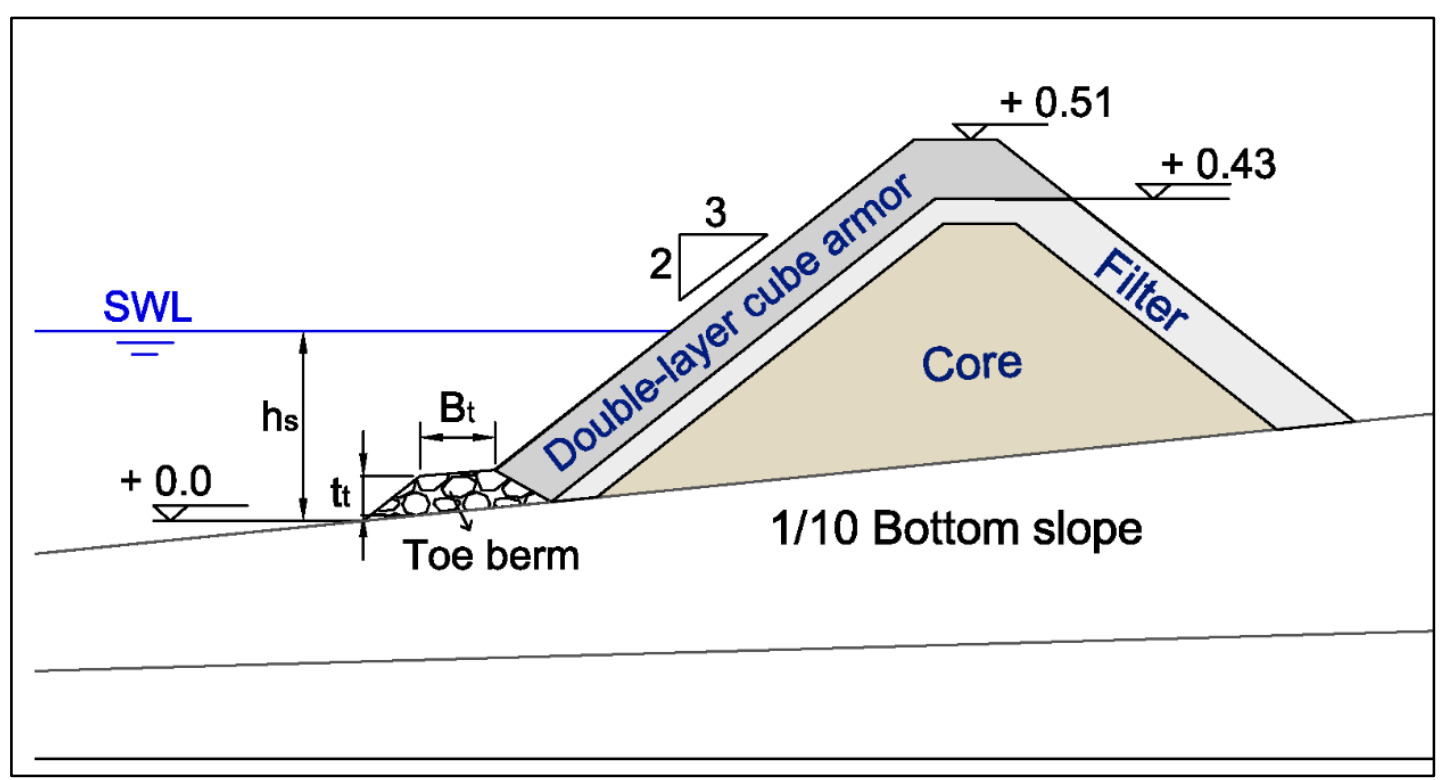

Fig. 5. Cross section of the cube armored model (dimensions in meters).

Random wave runs of 500 waves were generated following JONSWAP $(\gamma=3.3)$ spectra, and incident and reflected waves were estimated at the wave generating zone (wave gauges G1, G2 and G3). The AWACS Active Absorption System was activated to avoid multi-reflections.

Test series were associated to the water depth at the toe $\left(h_{s}\right)$. For a specific $h_{s}$, five different peak periods were used, $T_{p}(s)=1.20,1.50,1.80,2.20$ and 2.40 ; for each peak 
period $\left(T_{p}\right)$, increasing values of significant wave height at the wave generating zone $\left(H_{s g}\right)$ were produced from no damage to wave breaking. $H_{s g}$ was varied in steps of $2 \mathrm{~cm}$ in the range of $8<H_{s g}(\mathrm{~cm})<22$. The tested water depths at the toe of the structure were $h_{s}(\mathrm{~cm})=-2,0,2,4,6,8,10,12,14,16,18$ and 20 .

The methodology used in these experiments considered the fact that on steep seafloors and in very shallow waters seawalls must withstand not just a design storm, but also numerous wave storms slightly less intense than the design storm. For each water depth $\left(h_{s}\right)$, five peak periods with approximately seven significant wave heights were generated. The toe berm was repaired after a test series of a specific $h_{s}$ (35 to 40 tests for each rock size tested: $D_{n 50}(\mathrm{~cm})=3.99$ and 5.17$)$. A total of 775 tests were performed.

Surface elevation was measured using eleven capacitive wave gauges, three acoustic gauges and four pressure sensors placed along the flume. One group of wave gauges (G1, G2 and G3) was placed near the wave generator while the other wave gauges were placed along the wave flume near the model (see Fig. 4). The distances (in meters) from wave gauges G9, G10 and G11 to the toe berm were 1.90, 1.40 and 0.70, respectively.

The damage to the toe berm was measured after each test. The damage parameter, $N_{\text {od, }}$ was obtained considering the cumulative number of rocks displaced from the toe berm during each test series ( $h_{s}$ constant). Comparing the photographs taken perpendicularly to the armor slope after each test, armor damage was also measured using the Virtual Net method described by Gómez-Martín and Medina (2014). 


\section{Data analysis}

\subsection{Wave analysis}

Using the measured surface elevations, wave height distributions and spectral moments were obtained. In several tests performed for this study, the water depth at the toe was null or negative $\left(h_{s}<h_{t}<0\right)$. Only in tests conducted with $h_{s}(\mathrm{~cm}) \geq 8$, was it possible to obtain reliable values for wave heights near the structure. Fig. 6 shows a comparison between $H_{m o}$ measured in the wave gauge $\mathrm{G} 1$ (wave generation zone) and G11 (model zone) for tests conducted in the range $8 \leq h_{s}(\mathrm{~cm}) \leq 20$.

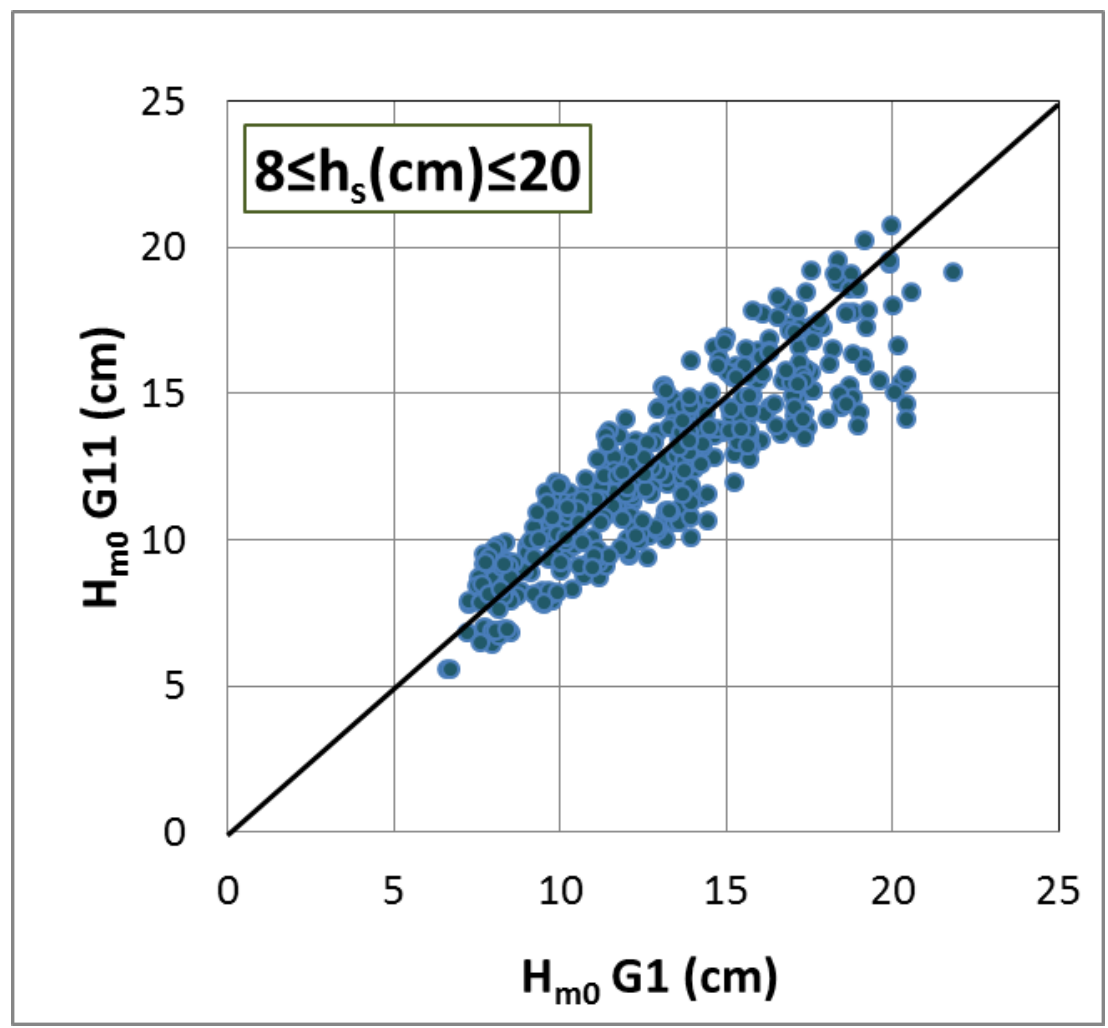

Fig. 6. Comparison between $H_{m o}$ measured in the wave gauge $\mathrm{G} 1$ and $\mathrm{G} 11$ for tests conducted in the range $8 \leq h_{s}(\mathrm{~cm}) \leq 20$. 
Thus, it was necessary to refer all measurements to a location independent from the toe berm. The deep water wave conditions were selected as a clear reference for wave characteristics in these experiments. Using the three wave gauges placed near the wave generator, incident and reflected waves were separated into non-linear and nonstationary waves using the LASA-V method developed by Figueres and Medina (2004). The incident significant wave heights measured at the wave generating zone were propagated to deep water using the shoaling coefficients proposed by Goda (2000).

In these conditions, it is not clear 'a priori' if wave transformation corresponding to the steep sea bottom $m=1 / 10$ in the wave breaking zone is different depending on the foreshore. In order to check the sensitivity of $H_{s}$ to the foreshore, a simple numerical experiment was conducted. To this end, the numerical model SwanOne (see Verhagen et al., 2008) was used to compare the significant wave height estimated at several points near the structure $(A, B, C, D, E, F, G, H$ and $T)$ in three virtual wave flumes with different configurations for the sea bottom (see Fig. 7). Flume \#1 (Fig. 7a) corresponds to the configuration used in the experiments; flume \#2 (Fig. 7b) and flume \#3 (Fig. 7c) consider different lengths of the bottom slope $m=1 / 10$ and different water depths at the wave generator.

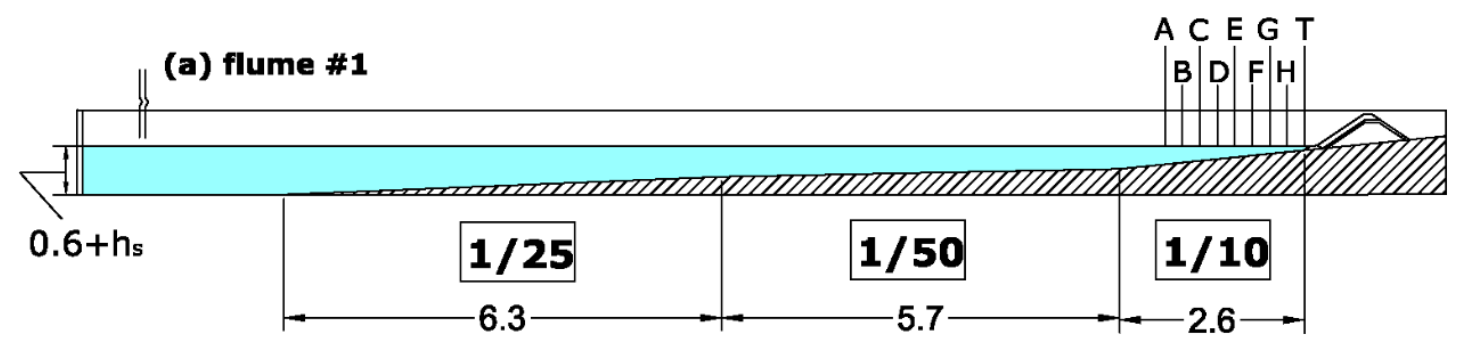



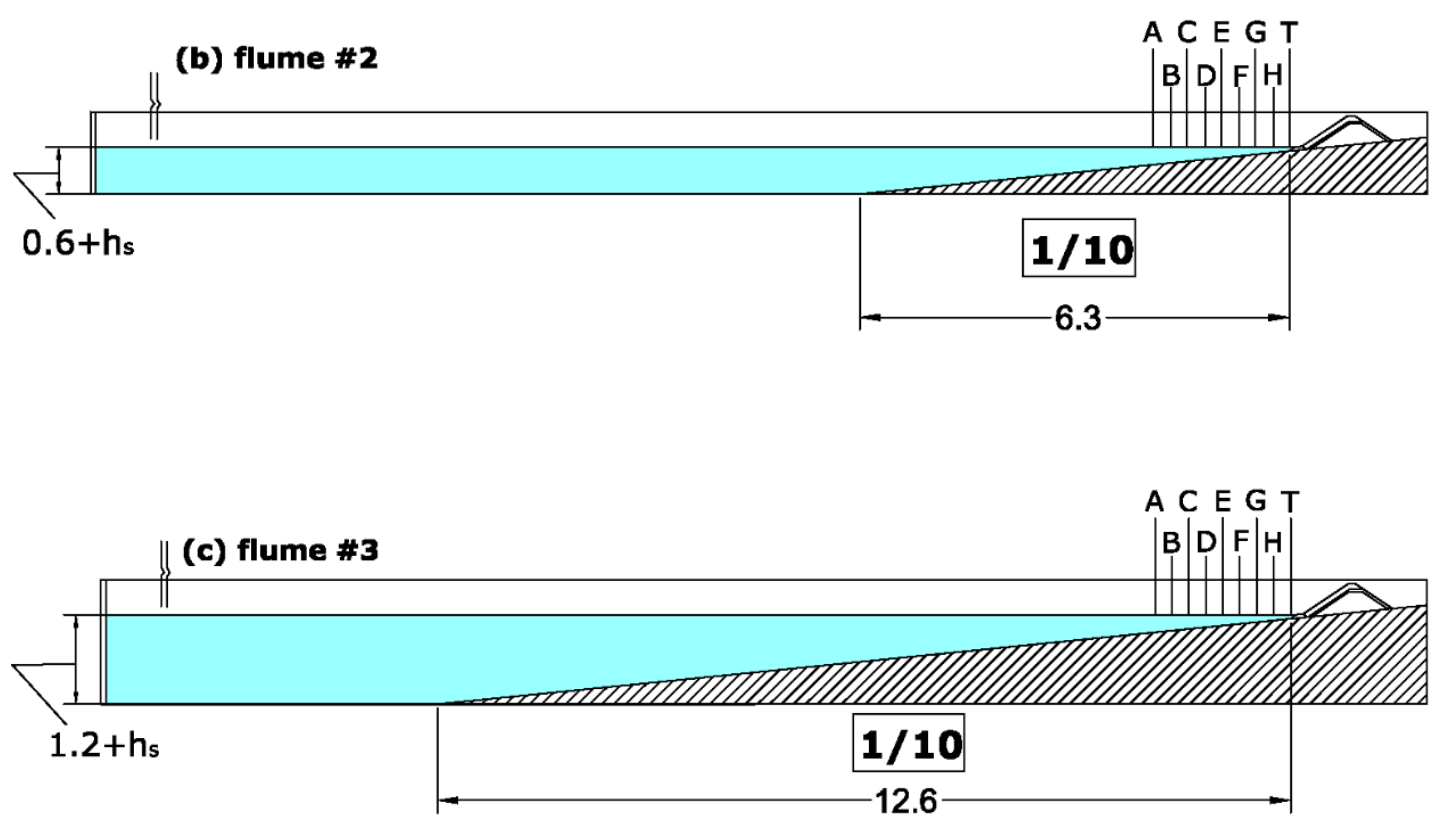

Fig. 7. Virtual wave flumes: (a) flume \#1, (b) flume \#2 and (c) flume \#3 (dimensions in meters).

The analysis considered different water depths at the toe $\left(h_{s}\right)$, peak periods $\left(T_{p}\right)$ and deep water significant wave heights $\left(H_{s 0}\right)$. Table 2 shows the input data used for the SwanOne model. $H_{s t}$ values, given by SwanOne at the toe of the structure, were taken as reference to characterize the bottom profile's influence on waves attacking the structure. The input energy in the model was exactly the same; the same deep water significant wave height $\left(H_{s 0}\right)$ and peak period $\left(T_{p}\right)$ were applied for the three virtual flumes.

Table 2. Significant wave height at the toe $\left(H_{s t}\right)$ as provided by the SwanOne numerical model for the virtual wave flumes \#1, \#2 and \#3, shown in Fig. 7.

\begin{tabular}{c|c|c|c}
\hline Deep water & \multicolumn{2}{|c|}{ Toe } & Toe \\
\hline Input data & Depth & $H_{s t}$ & Relative $H_{s t}$ \\
\hline
\end{tabular}




\begin{tabular}{ccccccccc}
\hline Case & $\begin{array}{c}T_{p} \\
(\mathrm{~s})\end{array}$ & $\begin{array}{c}H_{s 0} \\
(\mathrm{~cm})\end{array}$ & $\begin{array}{c}h_{s} \\
(\mathrm{~cm})\end{array}$ & $\begin{array}{c}H_{s t} \# 1 \\
(\mathrm{~cm})\end{array}$ & $\begin{array}{c}H_{s t} \# 2 \\
(\mathrm{~cm})\end{array}$ & $\begin{array}{c}H_{s t} \# 3 \\
(\mathrm{~cm})\end{array}$ & $\begin{array}{c}H_{s t} \# 2 / H_{s t} \# 1 \\
(-)\end{array}$ & $\begin{array}{c}H_{s t} \# 3 / H_{s t} \# 1 \\
(-)\end{array}$ \\
\hline 1 & 1.2 & 11.4 & 4 & 4.78 & 4.69 & 4.77 & 0.981 & 0.998 \\
2 & 1.5 & 15.8 & 4 & 5.85 & 5.84 & 5.85 & 0.999 & 0.999 \\
3 & 2.2 & 16.8 & 4 & 5.92 & 5.92 & 5.91 & 1.000 & 0.999 \\
4 & 1.2 & 11.4 & 6 & 6.27 & 6.25 & 6.25 & 0.997 & 0.997 \\
5 & 1.5 & 15.6 & 6 & 7.43 & 7.43 & 7.46 & 0.999 & 1.004 \\
6 & 2.2 & 17.2 & 6 & 8.82 & 8.82 & 8.82 & 1.000 & 1.000 \\
7 & 1.2 & 10.9 & 14 & 9.68 & 9.68 & 9.44 & 1.000 & 0.975 \\
8 & 1.5 & 14.6 & 14 & 11.91 & 11.98 & 11.76 & 1.005 & 0.987 \\
9 & 1.8 & 15.3 & 14 & 12.67 & 13.01 & 12.90 & 1.027 & 1.019 \\
10 & 1.2 & 11.4 & 18 & 10.33 & 10.41 & 10.12 & 1.008 & 0.980 \\
11 & 1.5 & 15.8 & 18 & 13.46 & 13.53 & 13.21 & 1.006 & 0.982 \\
12 & 2.2 & 17.7 & 18 & 16.27 & 16.37 & 16.51 & 1.006 & 1.015 \\
\hline
\end{tabular}

The relative mean squared error ( $r M S E)$ was used to measure the error between two significant wave heights estimated by the SwanOne numerical model for two virtual flumes. Flume \#1 was taken as reference (target) because it corresponds to the wave flume used for the physical experiments described in this study.

$r M S E=\frac{M S E}{\sigma^{2}(t)}=\frac{\frac{1}{N} \sum_{i=1}^{N}\left(t_{i}-e_{i}\right)^{2}}{\sigma^{2}(t)}$

where MSE is the mean squared error, $N$ is the number of observations, $t_{i}$ is the target value, $e_{i}$ is the estimated value and $\sigma^{2}$ is the variance of target values. The $r M S E$ estimates the proportion of variance in the target values $t_{i}(i=1$ to $N$ ) not explained by the estimated values, $e_{i}$. 
Table 3 shows the rMSE corresponding to points "A" to "T" when $H_{s}=\left(4 \cdot m_{0}\right)^{1 / 2}$ measured at the same point in flume \#1 is compared to $H_{s}$ measured in flumes \#2 and \#3. Input data for the SwanOne model are given in Table 2.

Table 3. rMSE corresponding to $H_{s}$ given by the SwanOne model at different points along wave flume \#1 (target) as compared to values given for flumes \#2 and \#3.

\begin{tabular}{cccc}
\hline \multicolumn{4}{c}{ rMSE } \\
\hline Point & $\begin{array}{c}\text { Toe distance } \\
(\mathrm{m})\end{array}$ & $H_{s} \# 2$ & $H_{s} \# 3$ \\
\hline A (G9) & 1.90 & 0.040 & 0.036 \\
B & 1.40 & 0.028 & 0.027 \\
C (G10) & 1.30 & 0.023 & 0.025 \\
D & 1.00 & 0.016 & 0.019 \\
E (G11) & 0.70 & 0.009 & 0.014 \\
F & 0.60 & 0.007 & 0.014 \\
G & 0.40 & 0.002 & 0.010 \\
H & 0.20 & 0.003 & 0.005 \\
T & 0.00 & 0.001 & 0.002 \\
\hline
\end{tabular}

At the toe of the structure, the $r M S E$ of $H_{s t}$ was $0.1 \%$ (flume \#2) and $0.2 \%$ (flume \#3). The $H_{s}$ errors were very low, especially at the points near the structure.

The results of this numerical experiment clearly indicate that changes in the bottom profile do not significantly affect the $H_{s}$ near the structure, if the toe is placed on a bottom slope $m=1 / 10$ (regardless of how far away the bottom profile is from the structure). Thus, when the breakwater is placed on a bottom slope $m=1 / 10$ in very shallow waters, the slope will determine the waves that can actually reach the toe berm. In this study, it was assumed that the wave storm attacking the structure 
depends only on the bottom slope $(m=1 / 10)$, water level and deep water wave storm characteristics.

One should take into account that deep water wave conditions are the obvious reference when dealing with incident and reflected waves breaking on the seafloor. Existing methods to separate incident and reflected waves on steep sea bottoms combined with shallow waters are not reliable when applied near the structure (Baldock and Simmonds, 1999; Battjes et al., 2004).

\subsection{Damage analysis}

The rocks displaced from the toe berm were counted after each test to calculate the damage number $N_{o d}$. Because this study deals with shallow water wave breaking conditions, the influence of the water depth on toe berm stability was analyzed first.

Fig. 8 shows the evolution of the observed toe berm damage depending on the water depth at the toe $\left(h_{s}\right)$ for tests with $D_{n 50}(\mathrm{~cm})=3.99$ and 5.17 . Roughly speaking, toe berm damage $\left(N_{o d}\right)$ increased with water depths up to $h_{s}(\mathrm{~cm})=12$, and decreased from there up to $h_{s}(\mathrm{~cm})=20$. 


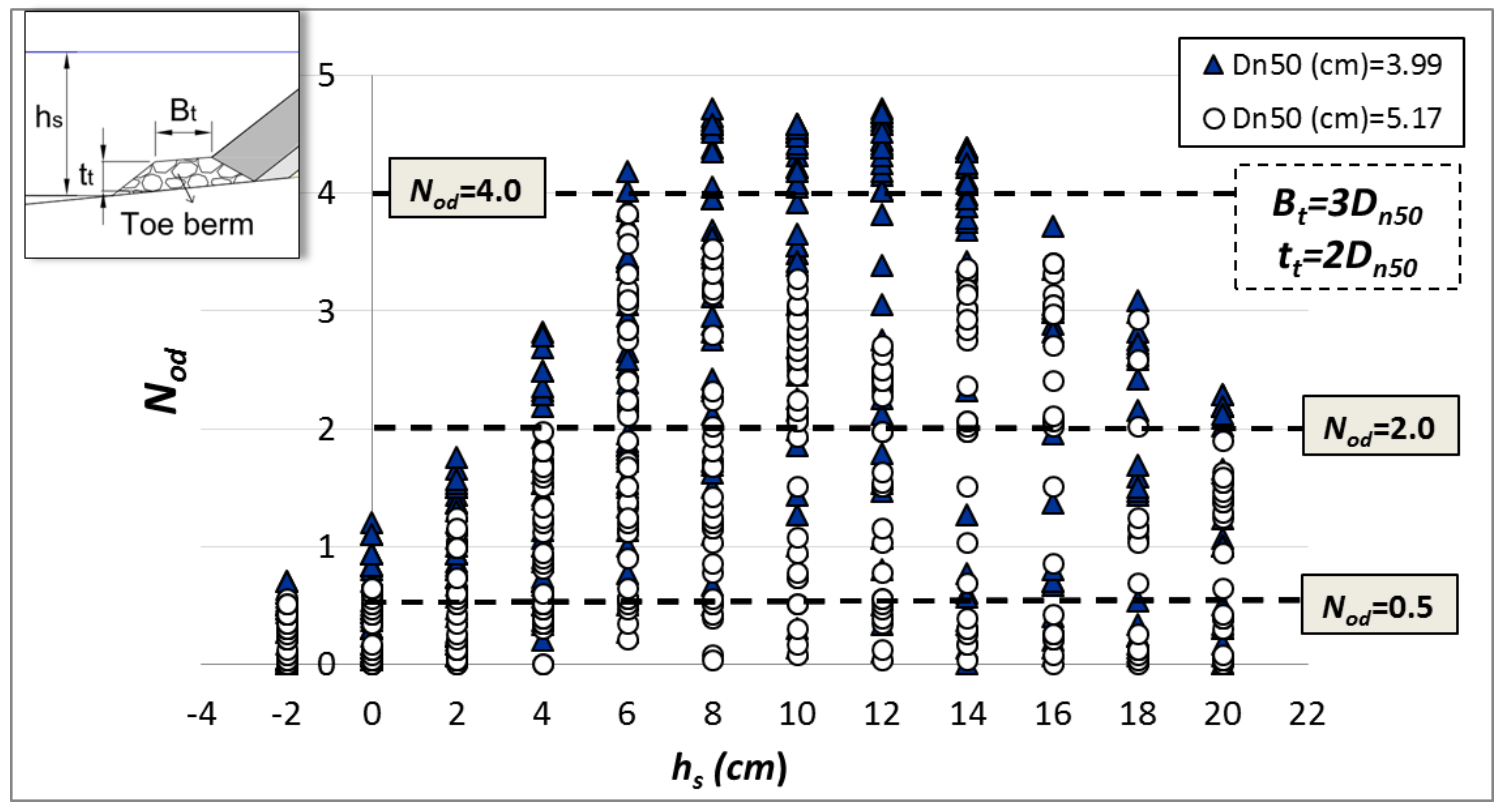

Fig. 8. Measured toe berm damage $\left(N_{o d}\right)$ depending on water depth at the toe $\left(h_{s}\right)$.

Most toe berm damage occurred during the run-down events. Run-up and run-down mainly depend on the wave height and period of incident waves. According to Hunt (1959), the run-up $\left(R_{\text {up }}\right)$ on a structure due to monochromatic waves can be estimated by Eq. (10).

$R_{\text {up }}=\left(H \cdot L_{0}\right)^{1 / 2} \cdot \tan \alpha$

where $\tan \alpha$ is the slope of the breakwater. Different formulas have been obtained to characterize wave run-up and run-down based on Eq. (10). Test results by Thompson and Shuttler (1975) indicated that the run-down level $\left(R_{d}\right)$ on porous slopes is also proportional to $\left(H \cdot L_{0}\right)^{1 / 2}$.

In the experiments conducted for this study, $N_{o d}$ seemed to increase almost linearly with the variable $\left(H_{s 0} \cdot L_{O p}\right)^{1 / 2}$ for a given water depth $\left(h_{s}\right)$ up to failure $\left(N_{o d} \approx 4.0\right)$. Fig. 9 
shows $N_{o d}$ as a function of $\left(H_{s 0} \cdot L_{o p}\right)^{1 / 2}$ and $h_{s}$, for tests carried out with $D_{n 50}(\mathrm{~cm})=3.99$ and 5.17. Straight lines correspond to $h_{s}(\mathrm{~cm})=-2,0,2,4$ and 6 .
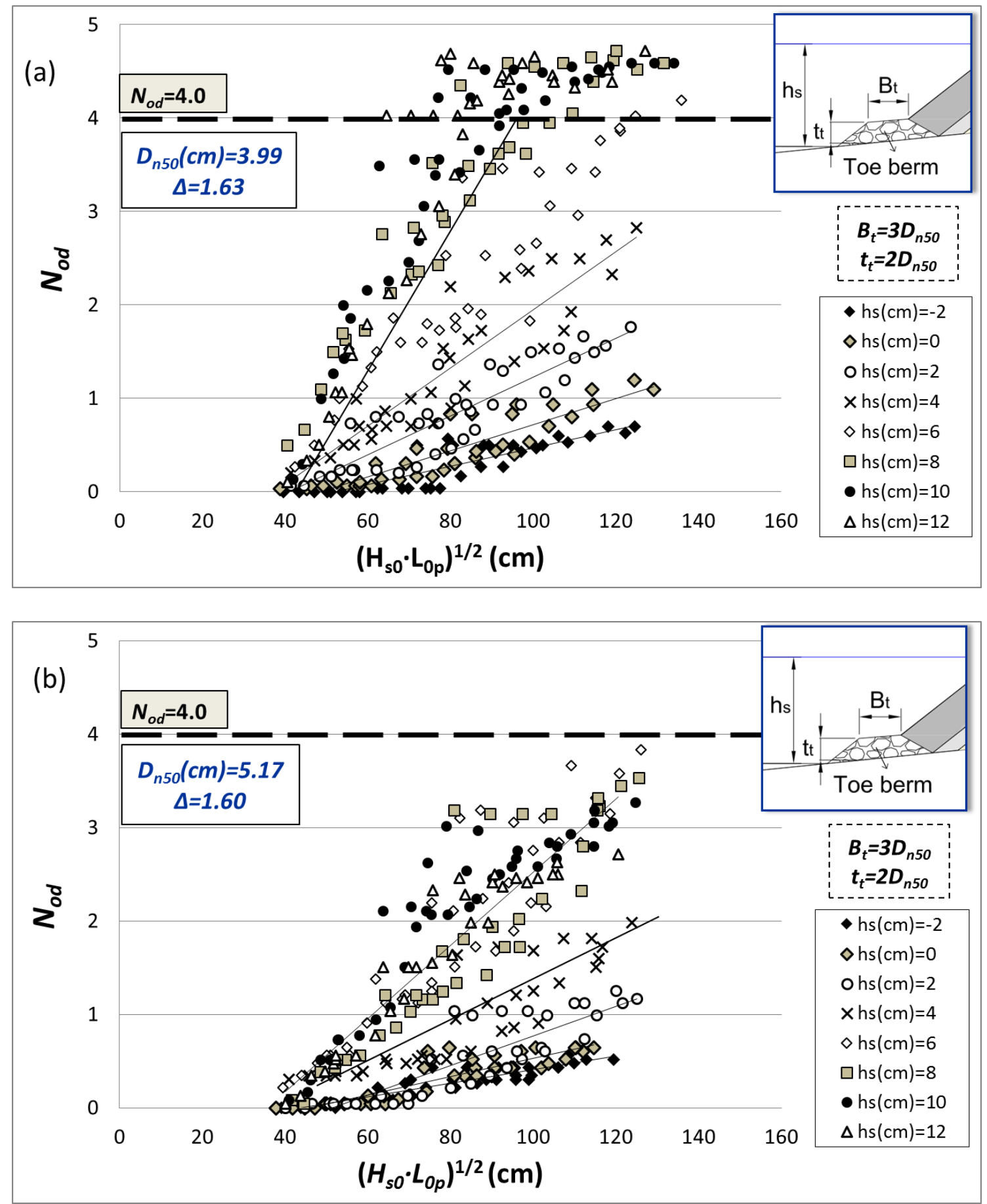

Fig. 9. Measured toe berm damage $\left(N_{o d}\right)$ compared with $\left(H_{s 0} \cdot L_{o p}\right)^{1 / 2}$. 
For toe berm damage $N_{o d}>4$, an increase in $\left(H_{s 0} \cdot L_{o p}\right)^{1 / 2}$ did not significantly increase the damage (failure according to CIRIA/ CUR/ CETMEF, 2007). Only tests with $N_{o d} \leq 4$ were selected for further analysis.

\section{A new toe berm stability formula}

A new design formula was developed in this study to include the most relevant parameters affecting the stability of toe berms placed on steep $(m=1 / 10)$ sea bottoms in combination with very shallow waters. The analysis in the previous section showed that toe berm damage was greater with increasing wave conditions, $\left(H_{s 0^{\circ}} L_{O p}\right)^{1 / 2}$, and decreasing rock size, $D_{n 50}$. Thus, the ratio $\left(H_{s 0} \cdot L_{0 p}\right)^{1 / 2} / \Delta D_{n 50}$ was used as an explanatory dimensionless parameter for the design equation. The influence of the water depth was introduced using the relative water depth $\left(h_{s} / D_{n 50}\right)$, which is a structural dimensionless variable independent from the climate conditions. As $N_{o d}$ increased with $\left(H_{s 0} \cdot L_{0 p}\right)^{1 / 2} / \Delta D_{n 50}$ as a function of $h_{s} / D_{n 50}$ (see Fig. 10), the corresponding general formula is given by Eq.(11).

$N_{\text {od }}=\left(\frac{\left(H_{s 0} \cdot L_{0 p}\right)^{1 / 2}}{\Delta D_{n 50}}-c\right) \cdot f\left(\frac{h_{s}}{D_{n 50}}\right)$

in which $c$ is a constant, and $f\left(h_{s} / D_{n 50}\right)$ is a function of the relative water depth $h_{s} / D_{n 50}$.

To calibrate the general expression of the design formula, only tests corresponding to the maximum significant wave height generated for each peak period and water depth were taken into account. In each test series defined by a water depth at the toe $\left(h_{s}\right)$, cumulative toe berm damage $\left(N_{o d}\right)$ generally increased with increasing deep water significant wave height $\left(H_{s 0}\right)$ and peak period $\left(T_{p}\right)$. However, for a specific $T_{p}$, only the 
higher $H_{s 0}$ significantly increased the toe berm damage $N_{o d}$. Therefore, only the toe berm damage value obtained at the highest $H_{s o}$ of each $T_{p}$ was considered for calibration purposes.

One should take into account that the toe berm damage associated to a specific water level $\left(h_{s}\right)$ and wave condition $\left(H_{s 0}, T_{p}\right)$, refers to the cumulative damage of the previous tests with lower $H_{s 0}$ and $T_{p}$, and the same $h_{s}$.

The new formula for toe berm design is obtained by calibrating $c$ and $f\left(h_{s} / D_{n 50}\right)$ in Eq. (11) with the test results from this study. $f\left(h_{s} / D_{n 50}\right)$ considers that given $D_{n 50}, H_{s 0}$ and $T_{p}, N_{o d}$ is highest when $h_{s} / D_{n 50}=3.0\left(h_{t} / D_{n 50}=1\right)$. From $h_{s} / D_{n 50}=3.0, N_{o d}$ decreases with increasing $h_{s} / D_{n 50}$

$N_{\text {od }}=\left(\frac{\left(H_{s 0} \cdot L_{0 p}\right)^{1 / 2}}{\Delta D_{n 50}}-5.5\right) \cdot\left[\left(-0.2 \frac{h_{s}}{D_{n 50}}+1.4\right) \cdot \exp \left(0.25 \frac{h_{s}}{D_{n 50}}-0.65\right)\right]^{1 / 0.15}$

Eq. (12) is valid for a standard toe berm $\left(B_{t}=3 \cdot D_{n 50}\right.$ and $\left.t_{t}=2 \cdot D_{n 50}\right)$ placed on a steep seafloor $(m=1 / 10)$ in the range $N_{o d} \leq 4.0,0.02<s_{0 p}=2 \pi H_{s o} / g T_{p}^{2}<0.07,-0.15<h_{s} / H_{s 0}<1.5$ and $-0.5<h_{s} / D_{n 50}<5.01$.

Fig. 10 compares the test results and the proposed formula (Eq. (12)) corresponding to four relative water depths, in which the toe berm was completely emerged $\left(h_{s} / D_{n 50}=-\right.$ $0.4)$, partially emerged $\left(h_{s} / D_{n 50}=0.8\right.$ and 1.5$)$ and submerged $\left(h_{s} / D_{n 50}=3.0\right)$. 


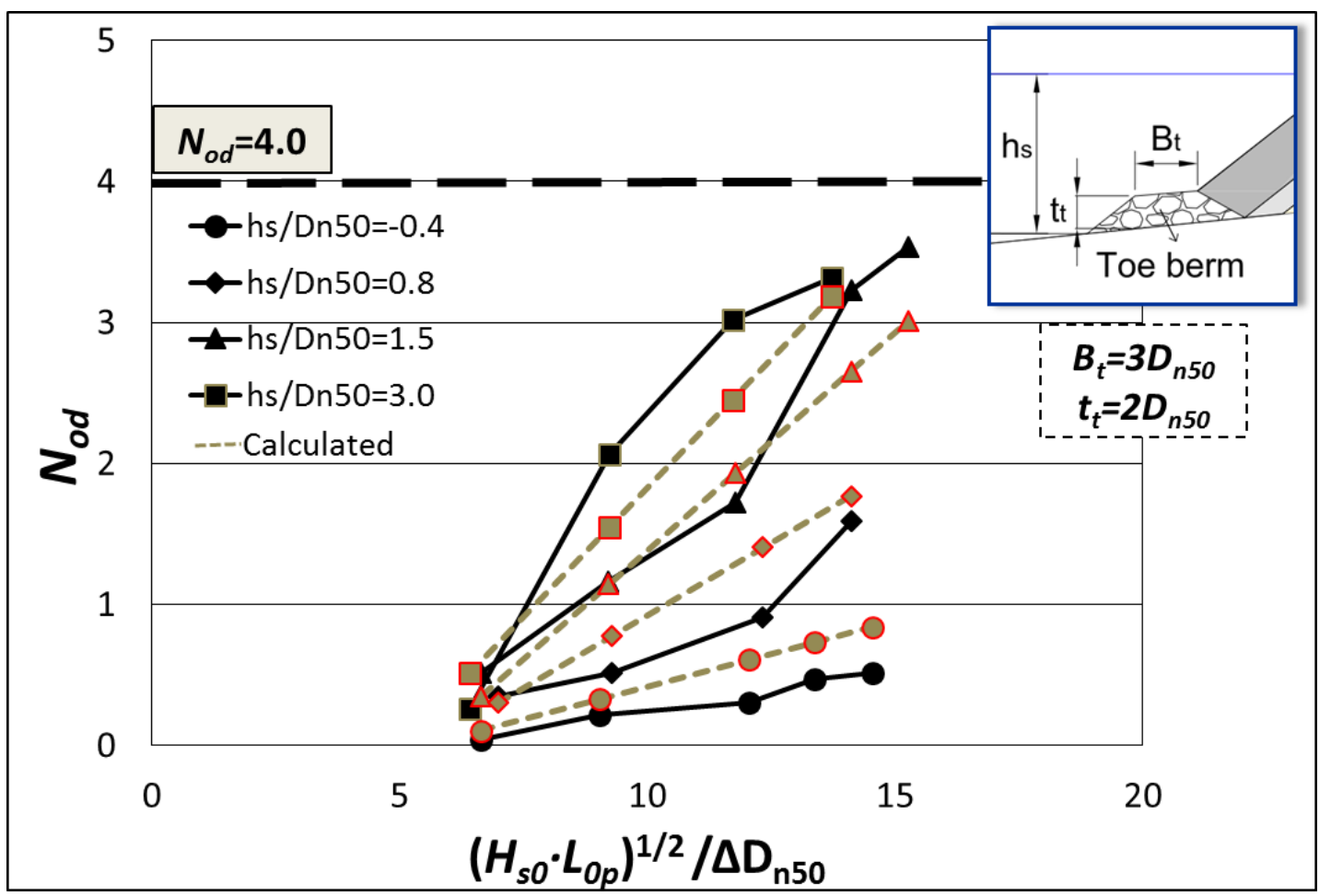

Fig. 10. Comparison of measured and estimated damage for emerged and submerged toe berms.

The agreement between measured and estimated $N_{o d}$ was reasonable as $N_{o d}$ errors were lower than 0.5. The goodness of fit considering all measured and calculated values is described in the next section.

\subsection{Confidence intervals for the new stability formula}

Assuming a Gaussian error distribution, the $90 \%$ confidence interval for the toe damage estimation given by Eq. (12) is:

$N_{\text {od }} \mid \begin{aligned} & 5 \% \% \\ & 5 \%\end{aligned}=N_{o d} \pm 1.64 \cdot \sqrt{\sigma^{2}(\varepsilon)}$

where $N_{o d}$ is given by Eq. (12) and $\sigma^{2}(\varepsilon)$ is the variance of the estimation errors. $\sigma^{2}(\varepsilon)$ was not considered as constant but rather as a linear function of $N_{o d}$ given by Eq. (14). 
$N_{o d}$ data were ordered and grouped in ten data sets as shown in Fig. 11. The MSE was calculated for each data set (black rhombus in Fig. 11). As the MSE increases with increasing $N_{o d}$, the variance of the errors can be estimated by:

$\sigma^{2}(\varepsilon)=0.14 \cdot N_{o d}+0.05$

where $N_{o d}$ is given by Eq. (12). The $90 \%$ confidence interval is given by:

$N_{\text {od }} \mid \begin{aligned} & 5 \% \\ & 5 \%\end{aligned}=N_{\text {od }} \pm 1.64 \cdot \sqrt{\left(0.14 \cdot N_{o d}+0.05\right)}$

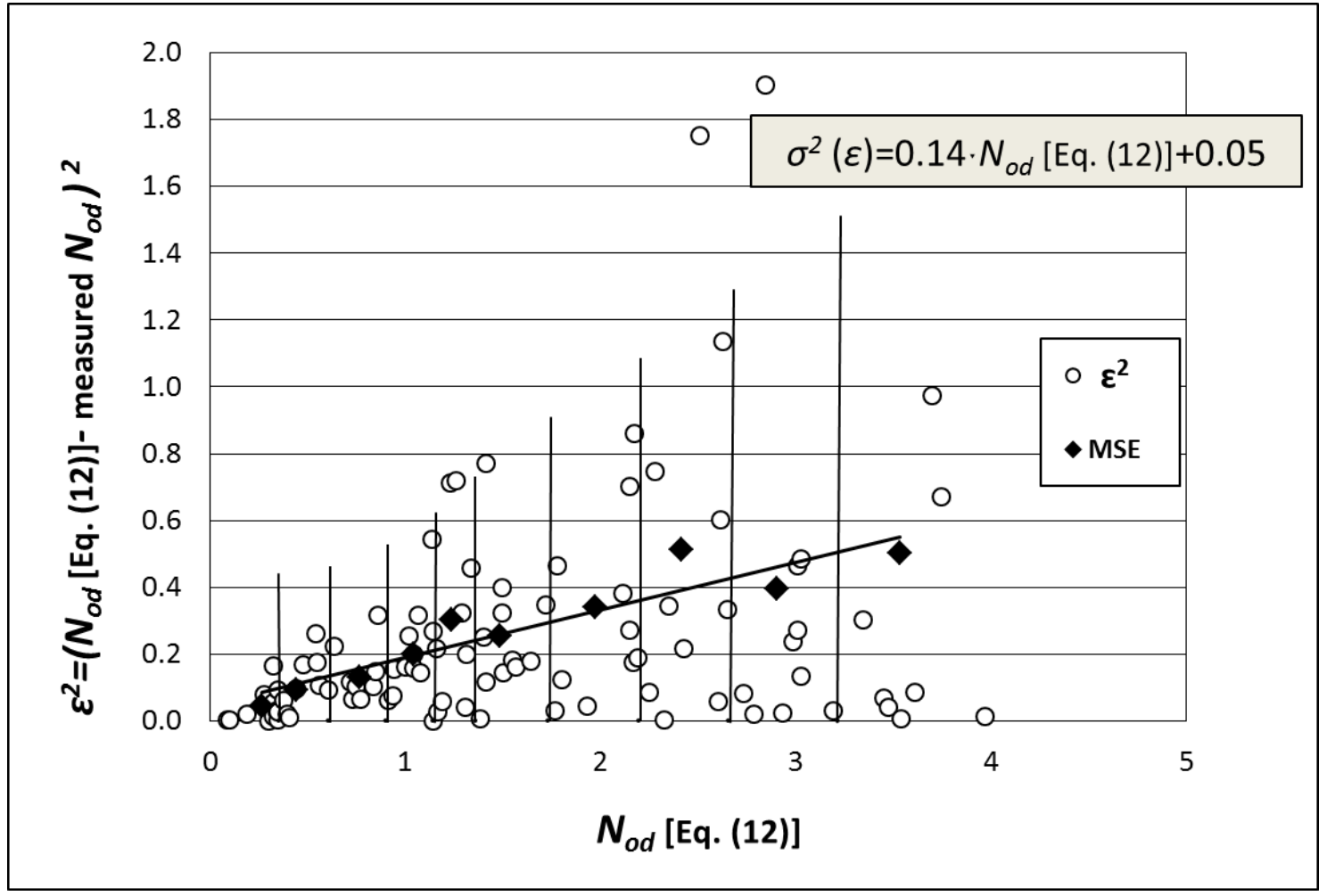

Fig. 11. Squared toe berm damage errors as a function of the $N_{o d}$ given by Eq. (12).

Fig. 12 compares measured $N_{o d}$ and estimated $N_{o d}$ given by Eq. (12) as well as the $90 \%$ confidence interval given by Eq. (15). The rMSE and the correlation coefficient $(R)$ were 
used to determine the goodness of fit between the values of $N_{o d}$ measured in tests and the $N_{o d}$ given by Eq. (12).

$$
R=\frac{\sum_{i=1}^{N}\left(t_{i}-\mu_{t}\right)\left(e_{i}-\mu_{e}\right)}{\sqrt{\sum_{i=1}^{N}\left(t_{i}-\mu_{t}\right)^{2} \sum_{i=1}^{N}\left(\mathrm{e}_{i}-\mu_{e}\right)^{2}}}
$$

where $N$ is the number of observations, $t_{i}$ is the target value, $e_{i}$ is the estimated value and $\mu_{\mathrm{t}}$ and $\mu_{\mathrm{e}}$ are the sample means of target and estimated values, respectively.

The $r M S E=1-\mathrm{R}^{2}=0.208$ indicates the proportion of variance of $N_{o d}$ not explained by Eq. (12) and $R=0.89$, the degree of correlation between measured and estimated values of $N_{o d}$

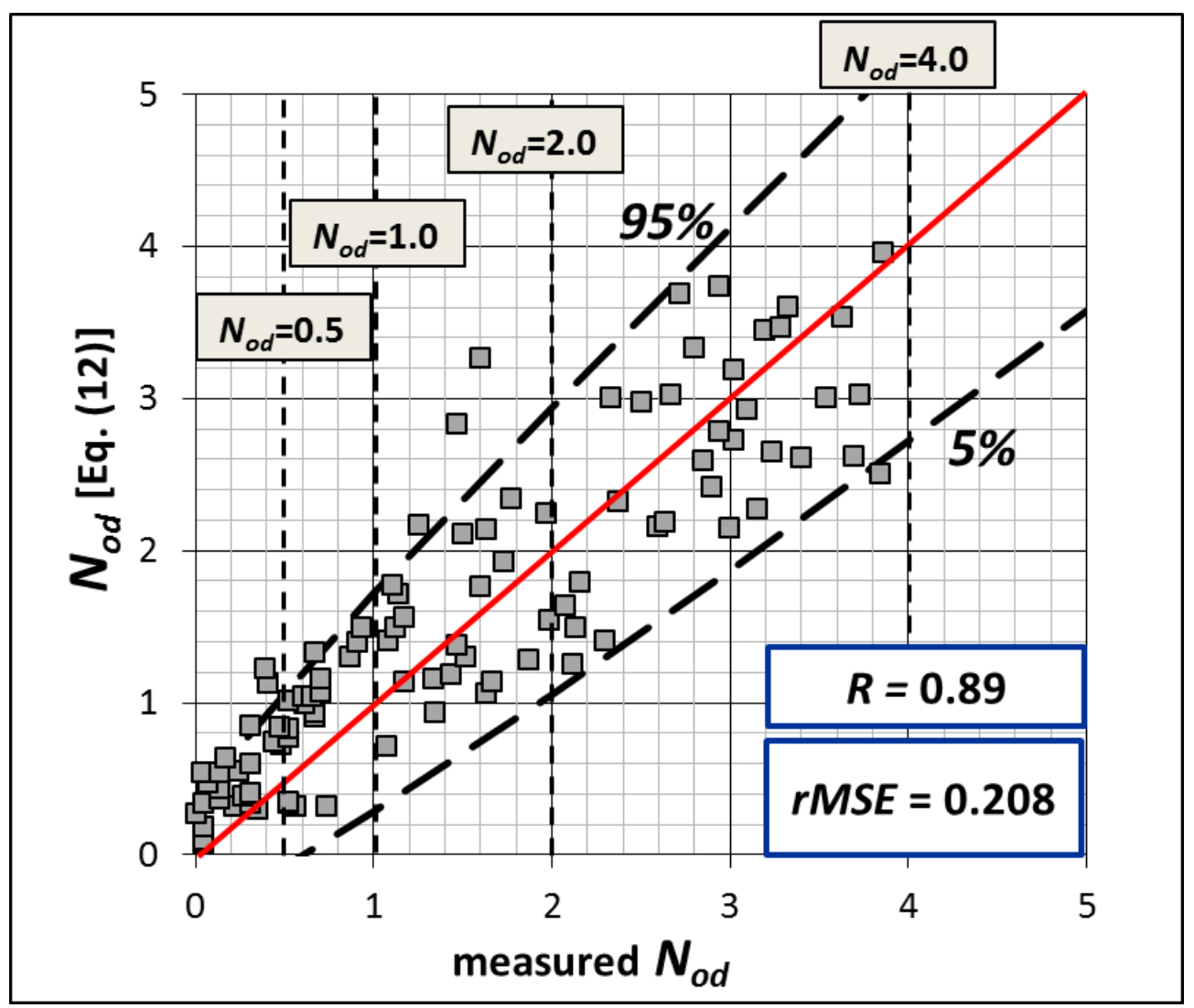


Fig. 12. Comparison of the $N_{o d}$ measured in tests and the $N_{o d}$ given by Eq. (12) and $90 \%$ confidence interval.

\subsection{Validation with additional tests}

In order to validate the new toe berm design formula given by Eq. (12), those tests carried out with lower wave heights, and not considered to calibrate Eq. (12), were used. Only tests with parameters defined within the range of application of Eq. (12) were taken into account in this analysis.

Fig. 13 compares the measured toe berm damage $N_{o d}$ and the estimated $N_{o d}$ using Eq. (12). Most validation test results fall within the $90 \%$ confidence interval, and the $r M S E$ was 0.124 . Thus, Eq. (12) is valid for all data within the specified range of application.

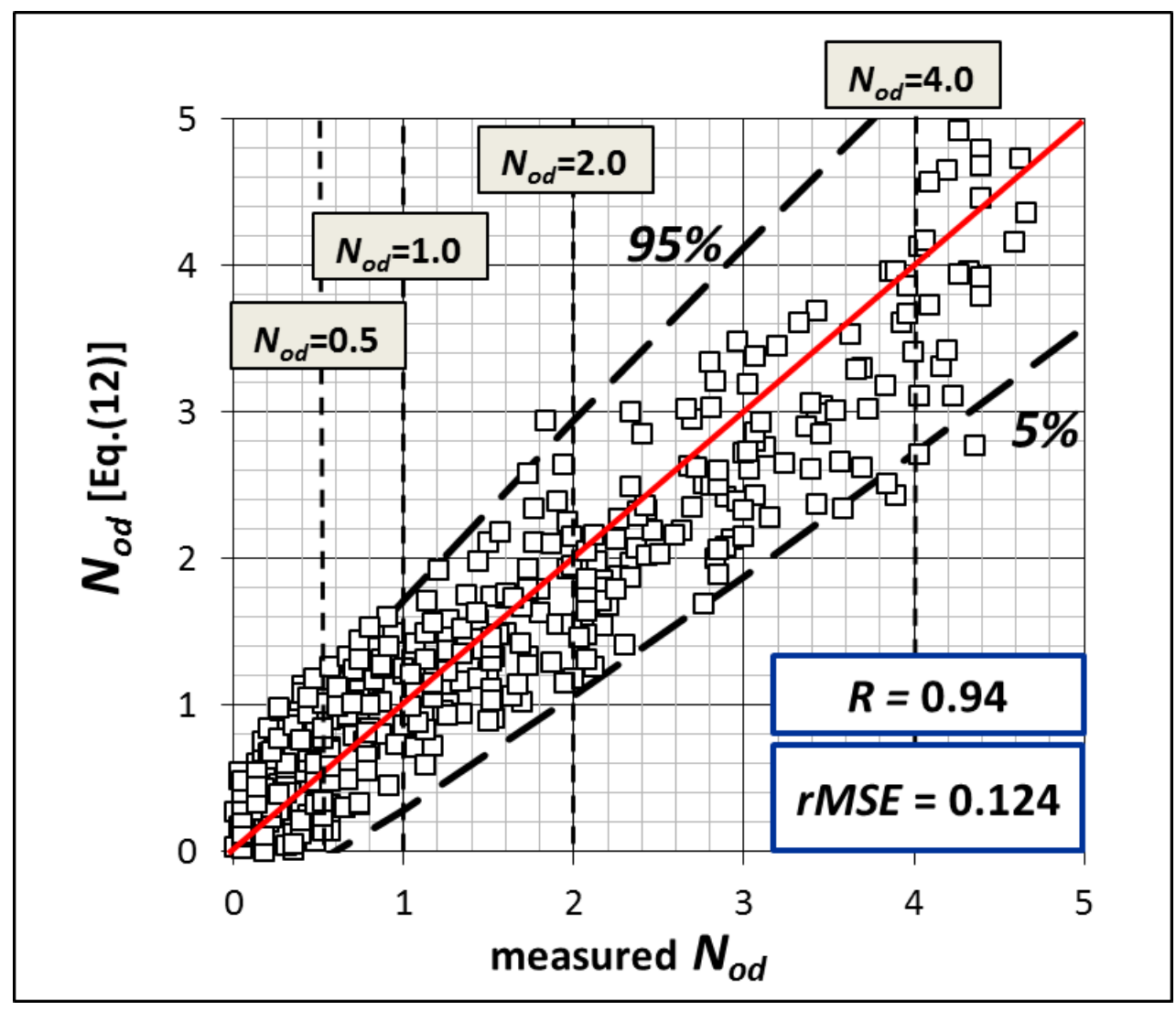


Fig. 13. Comparison of the $N_{o d}$ measured in tests and the $N_{o d}$ given by Eq. (12) and $90 \%$ confidence intervals given by Eq. (15) for all tests within the range of application specified for Eq. (12).

From the qualitative point of view, four levels of toe berm damage were distinguished in this study: (1) no significant movement of toe berm rocks $\left(N_{o d}<0.5\right)$, (2) significant rock movements $\left(N_{o d}=1.0\right)$, (3) moderate damage but toe berm still providing support to the armor $\left(N_{o d}=2.0\right)$, and $(4)$ toe berm failure $\left(N_{o d}=4.0\right)$.

Using this damage scale, a value of $N_{o d}=1.0$ is considered a reasonable design criteria when using Eq. (12). If the toe berm is much larger than the standard size tested in this study $\left(B_{t}=3 \cdot D_{n 50}\right.$ and $\left.t_{t}=2 \cdot D_{n 50}\right)$, the design criteria $N_{o d}=1.0$ and the new formula are no longer valid (see Van Gent and Van der Werf, 2014).

\subsection{Comparison of measurements with existing formulas}

As mentioned in Section 2, different formulas can be used to predict toe berm damage (Eqs. (3), (4) and (6) to (8)). Although they were obtained from laboratory tests with different conditions and foreshore slopes, a comparison was made between the toe berm damage measured in this study and the predictions given by these five formulas. Only tests conducted with submerged toe berms $\left(h_{t}>0\right)$ were compared because emerged toe berms are out of the range of applicability of the formulas given in the literature. The significant wave height obtained in this study in the gauge G11 was used to estimate the wave height at the toe in the prediction formulas.

Fig. 14 shows the $N_{o d}$ measured in this study and the toe berm damage prediction given by Eqs. (3), (4) and (6) to (8) for those tests conducted in the range $10 \leq h_{s}(\mathrm{~cm})$ 
$\leq 20\left(h_{t}>0\right)$. The $90 \%$ confidence intervals of the proposed equation (Eq. (12)) are also depicted in Fig. 14.
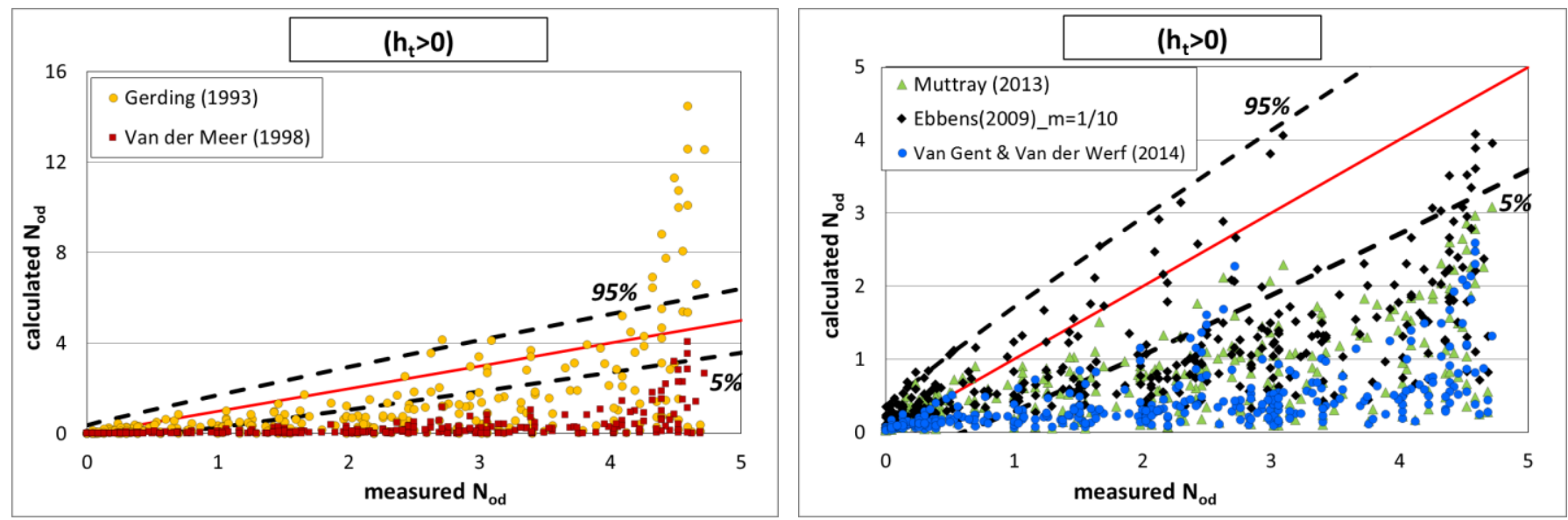

Fig. 14. Measured damage $\left(N_{o d}\right)$ compared with prediction formulas and $90 \%$ confidence intervals of Eq.(12) for submerged toe berms $\left(h_{t}>0\right)$.

Only tests performed with water depths in the range $10 \leq h_{s}(\mathrm{~cm}) \leq 20$ were compared; however, the validity of most of the equations is limited to relatively deep submerged toe berms placed in gentler seafloors. Eq. (12) usually provides conservative predictions of toe berm damage $N_{\text {od }}$ compared to the other formulas given in the literature, for toe berms in shallow water depths.

\subsection{Applications}

In this section, Eq. (12) is applied to a standard rock toe berm $\left(B_{t}=3 \cdot D_{n 50}\right.$ and $t_{t}=$ $\left.2 \cdot D_{n 50}\right)$ within the aforementioned validity ranges. Small, medium and large rocks were considered $(\mathrm{W}(\mathrm{t})=3,6$ and 12$)$ with a mass density of $\rho_{r}\left(\mathrm{t} / \mathrm{m}^{3}\right)=2.70$. A typical design storm for the Alboran Sea area was assumed $\left(H_{s 0}(\mathrm{~m})=6\right.$ and $\left.T_{p}(\mathrm{~s})=12\right)$. 
Fig. 15 depicts the toe berm damage ( $\left.N_{o d}\right)$ given by Eq. (12) depending on $h_{s} / D_{n 50}$ when considering $H_{s 0}(\mathrm{~m})=6$ and $T_{p}(\mathrm{~s})=12$ as the design wave storm. Toe berm damage is greatest when $h_{s} / D_{n 50}=3\left(h_{t}=D_{n 50}\right)$. In this case, failure $\left(N_{o d} \geq 4\right)$ or near failure is predicted for small, medium and large rocks. From $h_{s} / D_{n 50}=3\left(h_{t}=D_{n 50}\right)$, toe berm damage decreases with both increasing and decreasing water depths at the toe $\left(h_{t}\right.$ $>D_{n 50}$ and $\left.h_{t}<D_{n 50}\right)$. For the cases $h_{s} / D_{n 50}=0\left(h_{t}<<0\right)$ and $h_{s} / D_{n 50}=5\left(h_{t}>>0\right)$, low to moderate toe berm damage $\left(N_{o d}<2\right)$ is predicted when using toe berm rocks larger than $\mathrm{W}(\mathrm{t})=3\left(D_{n 50}=1.04\right)$.

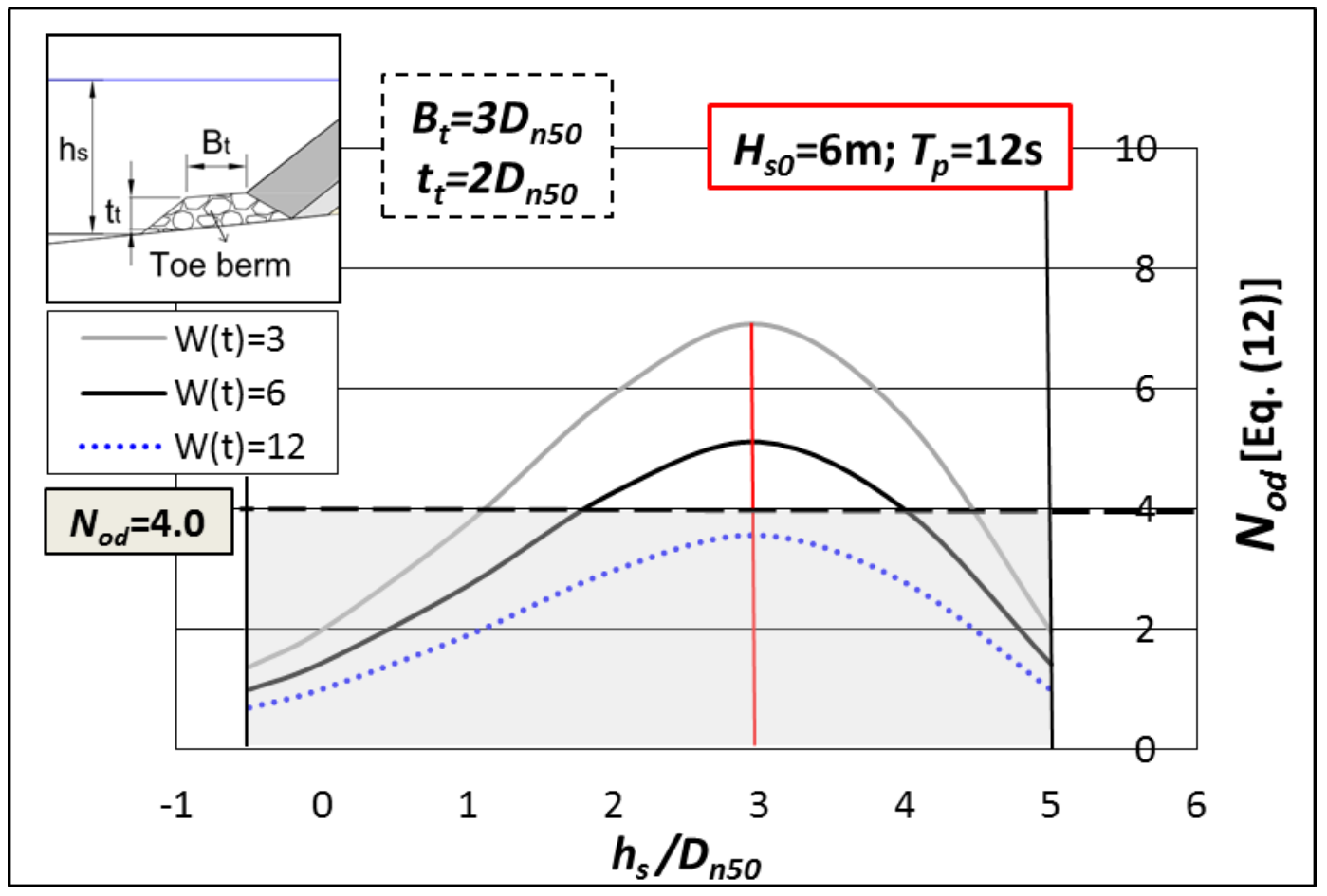

Fig. 15. Toe berm damage ( $\left.N_{o d}\right)$ given by Eq. (12) depending on $h_{s} / D_{n 50}$.

Eq. (12) can be used to determine a more stable toe berm position, changing the strictly submerged toe berm to an emerged or completely submerged toe berm within the range $-0.5<h_{s} / D_{n 50}<5.0\left(-2.5<h_{t} / D_{n 50}<3.0\right)$. If large rocks are not available at the construction site, the structure design should be modified, for instance, moving the 
toe berm to a deeper position, where the same toe berm is more stable, or using concrete units for the toe berm.

Toe berm damage also varies with the design wave storm. Fig. 16 shows the influence of the design wave storm on toe berm damage if $h_{s} / D_{n 50}=0$. When considering $H_{s 0}(\mathrm{~m})$ $=6$ and $T_{p}(\mathrm{~s})=12$, low damage is estimated with medium-sized rocks $\left(N_{o d} \approx 1\right)$. If waves are stronger, for instance $H_{s o}(\mathrm{~m})=8$ and $T_{p}(\mathrm{~s})=14$, moderate damage $\left(N_{o d} \approx 2\right)$ is estimated for this rock size $\left(\mathrm{W}(\mathrm{t})=6, D_{n 50}=1.30\right)$.

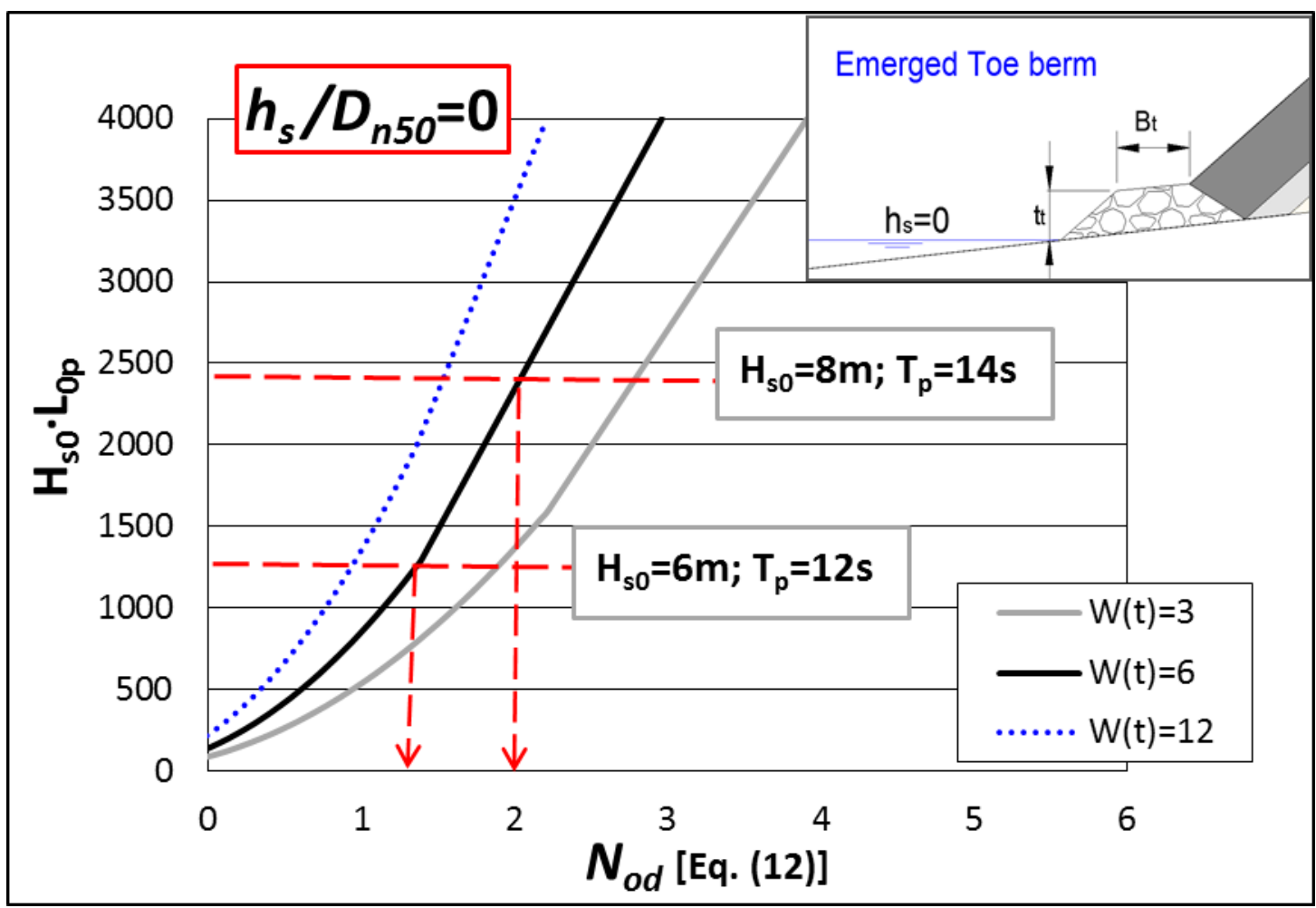

Fig. 16. Toe berm damage ( $\left.N_{o d}\right)$ given by Eq. (12) for $h_{t}<<0$ and $h_{s} / D_{n 50}=0$.

Formulas given in the literature are only valid for submerged toe berms $\left(h_{t}>>0\right)$. Thus, the case $h_{s} / D_{n 50}=5\left(h_{s} / D_{n 50}=3\right)$ is compared with equations given in Section 2, although Eqs. (3), (4) and (8) are out of the range of application. 
Table 4 shows the toe berm damage $\left(N_{o d}\right)$ estimated by Eqs. (3), (4), (6), (7), (8) and (12) for the specified rock sizes tested $(W(t)=3,6$ and 12$)$ with $B_{t}=3 \cdot D_{n 50}, t_{t}=2 \cdot D_{n 50}$ and the design wave storm $H_{s 0}(m)=6$ and $T_{p}(s)=12$. For Eqs. (3), (4), (6), (7) and (8), the specified design wave storm was propagated from deep water to the water depth $h_{s}=$ $5 \cdot D_{n 50}$ using the SwanOne numerical model to calculate the significant wave height at the toe, $H_{s t}$.

Table 4. Toe berm damage $\left(N_{o d}\right)$ estimated with (3), (4), (6), (7) and (8) for three rock sizes $(\mathrm{W}(\mathrm{t})=3,6$ and 12$)$ and $h_{s} / D_{n 50}=5$.

\begin{tabular}{ccccccc}
\hline \multicolumn{1}{c}{$N_{\text {od }}$} \\
\hline $\begin{array}{c}\text { Gerding } \\
(1993)\end{array}$ & $\begin{array}{c}\text { Van der } \\
\text { Meer (1998) }\end{array}$ & $\begin{array}{c}\text { Ebbens } \\
(2009)\end{array}$ & $\begin{array}{c}\text { Muttray } \\
(2013)\end{array}$ & $\begin{array}{c}\text { Van Gent and Van } \\
\text { der Werf (2014) }\end{array}$ & This study \\
\hline W(t) & Eq. (3) ${ }^{\mathrm{b}}$ & Eq. (4) ${ }^{\mathrm{b}}$ & Eq. (6) $^{\mathrm{a}}$ & Eq. (7) & Eq. (8) & Eq. (12) \\
\hline 3 & 5.5 & 0.3 & $5.5^{\mathrm{b}}$ & 2.9 & 0.6 & 2.0 \\
\hline 6 & 1.9 & 0.1 & $3.2^{\mathrm{b}}$ & 1.6 & 0.4 & 1.4 \\
\hline 12 & 0.5 & 0.03 & 1.7 & 0.7 & 0.2 & 1.0 \\
\hline${ }^{\mathrm{a}} N_{o d}=10 \cdot N_{\%}$. & & & & &
\end{tabular}

${ }^{b}$ Out of the range of application.

To estimate toe berm damage with a steep sea bottom $m=1 / 10$, only Eqs. (6) and (7) can be taken for comparison because the other formulas are based on tests carried out with gentler bottom slopes ( $m=1 / 20, m=1 / 30$ or $m=1 / 50)$. Eqs. (4) and ( 8 ) provide similar values for $N_{o d}$ but lower than those obtained with Eq. (12) because toe berms on steep seafloors undergo direct wave attack due to plunging breakers, resulting in higher values for $N_{\text {od. }}$. Although Eqs. (3) and (4) were obtained from the same test database, Eq. (3) estimates higher values for $N_{o d}$. 
Eqs. (6), (7) and (12) provide similar values of $N_{\text {od }}$ for the largest rock size $(\mathrm{W}(\mathrm{t})=12$, $\left.D_{n 50}=1.66\right)$. Eq. (6) differs from Eqs. (7) and (12) especially when using small- and medium-sized rocks, but the estimated toe berm damage values are beyond its range of application.

\section{Conclusions}

The design of the toe berm which supports the armor layer is usually considered as a secondary element in mound breakwater designs. However, when the toe berm is built close to the water surface on a steep sea bottom, it must withstand high wave loads due to wave breaking directly on the toe berm. In this case, the toe berm stability is a critical element of the breakwaters and, thus, the toe berm may require stones larger than those used in the armor layer. A review of the existing literature regarding toe berm stability indicates that there is no reasonable method to design toe berms on steep sea bottoms in combination with very shallow waters.

Using quarrystones, most existing formulas for toe berm design (Eqs. (1) to (8)) are based on laboratory tests with gentle bottom slopes and toe berms below the SWL $\left(h_{s}>h_{t}>>0\right)$. In these conditions, toe berm damage usually decreases with increasing water depths at the toe, $h_{s}$. However, on rocky coastlines with steep sea bottoms, sea defenses may require emerged toe berms $\left(h_{t}<<0\right)$. Toe berms in very shallow waters behaves completely different from those built in non-breaking conditions, and toe berm damage shows a critical point when the $S W L$ is near the top of the berm $\left(h_{t}=\right.$ $\left.D_{n 50}\right)$. From $h_{t}=D_{n 50}$, toe berm damage decreases with increasing as well as decreasing water depth at the toe $\left(h_{t}>D_{n 50}\right.$ and $\left.h_{t}<D_{n 50}\right)$. 
Within the ranges $0.02<\mathrm{s}_{0 \mathrm{p}}<0.07,-0.15<\mathrm{h}_{\mathrm{s}} / \mathrm{H}_{\mathrm{s} 0}<1.5$ and $-0.5<\mathrm{h}_{\mathrm{s}} / \mathrm{D}_{\mathrm{n} 50}<5.01$, Eqs. (12) and (15) estimate the toe berm damage $\left(N_{o d} \leq 4\right)$ and $90 \%$ confidence interval for standard toe berms $\left(B_{t}=3 \cdot D_{n 50}\right.$ and $\left.t_{t}=2 \cdot D_{n 50}\right)$ placed on steep $(m=1 / 10)$ sea bottoms in very shallow waters. Using $N_{o d}=1.0$ as a design criteria is recommended since the toe berm still provides good support to the armor layer.

The rock material required for toe berms built in these conditions depends on three parameters: water depth at the toe $\left(h_{s}\right)$, deep water significant wave height $\left(H_{s 0}\right)$ and deep water wave length corresponding to the peak period $\left(L_{o p}\right)$. The toe berm damage given by Eq. (12) takes into account the cumulative toe berm damage which corresponds to numerous lower intensity wave storms. For a given water depth $\left(h_{s}\right)$, Eq. (12) considers the damage associated to the design storm $\left(H_{s 0}, T_{p}\right)$ and the cumulative damage of storms with lower or equal $T_{p}$ and $H_{s O}$.

The design of toe berms using quarrystone is usually feasible for emerged toe berms $\left(h_{t}<<0\right)$ and deeply submerged toe berms $\left(h_{t}>>0\right)$. However, there is a range of water depths at the toe $\left(h_{s}\right)$ which requires rocks larger than the size that may be available at some construction sites. In these situations, the toe position may be moved to deeper or shallower waters to avoid the critical water depth $\left(h_{t} \approx D_{n 50}\right)$; toe berms with concrete units may also be another design alternative.

\section{Acknowledgments}

The first author was financially supported through the FPU program (Formación del Profesorado Universitario) funded by the Spanish Ministry of Education (Ministerio de Educación, Cultura y Deporte) FPU13/01872. The authors also acknowledge financial 
support from the Spanish Ministry of Economy and Competitiveness (grant BIA201233967). The authors thank Debra Westall for revising the manuscript.

\section{$\underline{\text { References }}$}

Baldock, T.E. and Simmonds, D.J., 1999. Separation of incident and reflected waves over sloping bathymetry. Coastal Engineering, 38, 167-176.

Battjes, J.A., Bakkenes, H.J., Janssen, T.T. and van Dongeren, A. R., 2004. Shoaling of subharmonic gravity waves. Journal of Geophysical Research, 109, C02009, doi:10.1029/2003JC001863.

CIRIA, CUR, CETMEF, 2007. The Rock Manual. The Use of Rock in Hydraulic Engineering (2nd edition). C683, CIRIA, London.

Docters van Leeuwen, L., 1996. Toe stability of rubble-mound breakwaters. M.Sc. thesis Delft. Delft University of Technology, Delft.

Ebbens, R.E., 2009. Toe Structures of Rubble Mound Breakwaters. Stability in Depth Limited Conditions. M.Sc. thesis Delft. Delft University of Technology, Delft.

Figueres, M. and Medina, J.R., 2004. Estimation of incident and reflected waves using a fully non-linear wave model. Proc. 29th International Conference on Coastal Engineering, World Scientific, Singapore, 594-603.

Gerding, E., 1993. Toe Structure Stability of Rubble Mound Breakwaters. M.Sc. thesis Delft and Delft Hydraulics Report H1874. Delft University of Technology, Delft.

Goda, Y., 2000. Random seas and design of maritime structures ( ${ }^{\text {nd }}$ Edition). World Scientific Publishing, Singapore, ISBN 981-02-3256-X. 
Gómez-Martín, M.E. and Medina, J.R., 2014. Heterogeneus Packing and Hydraulic Stability of Cube and Cubipod Armor Units. J. Waterway, Port, Coastal, Ocean Eng., $140,100-108$.

Hudson, R.Y., 1959. Laboratory investigation of rubble-mound breakwaters. Journal of the Waterways and Harbors Division, ASCE, 85(WW3), 93-121.

Hunt, I.A., 1959. Design of Seawalls and Breakwaters, ASCE, 85(WW3), 123-152.

Markle, D.G., 1989. Stability of toe berm armor stone and toe buttressing stone on rubble-mound breakwaters and jetties, physical model investigation. Technical Report REMR-CO-12. U.S. Army Engineer Waterways Experiment Station, Vicksburg, Mississippi.

Muttray, M., 2013. A pragmatic approach to rock toe stability. Coastal Engineering, 82, $56-63$.

Thompson, D.M. and Shuttler, R.M., 1975. Riprap design for wind wave attack. A laboratory study in random waves. Report EX 707, Hydraulic Research, Wallingford. USACE, 2006. Coastal Engineering Manual. Engineer Manual 1110-2-1100, U.S. Army Corps of Engineers, Washington, D.C. (in 6 volumes).

Van der Meer, J.W., 1998. Geometrical Design of Coastal Structures. Pilarczyk, K.W. (Ed.), Seawalls, Dikes and Revetments. Balkema, Rotterdam.

Van Gent, M.R.A. and Van der Werf, I.M., 2014. Rock toe stability of rubble mound breakwaters. Coastal Engineering, 83, 166-176.

Verhagen, H.J., Van Vledder, G., Eslami Arab, S., 2008. A practical method for design of coastal structures in shallow water. Proceedings $31^{\text {st }}$ International Conference on Coastal Engineering. World Scientific vol 4, pp. 2912-2922. 
